\title{
Drug Resistance in Glioblastoma: The Two Faces of Oxidative Stress
}

\author{
Christophe Olivier ${ }^{1,2 *}$, Lisa Oliver ${ }^{2,3 *}$, Lisenn Lalier ${ }^{2,4}$ and François M. Vallette ${ }^{2,4}$ \\ ${ }^{1}$ Faculté des Sciences Pharmaceutiques et Biologiques, Nantes, France, ${ }^{2}$ Université de Nantes, INSERM, CRCINA, Nantes, \\ France, ${ }^{3} \mathrm{CHU}$ de Nantes, Nantes, France, ${ }^{4} \mathrm{LaBCT}$, ICO, Saint Herblain, France
}

OPEN ACCESS

Edited by:

Ana Cipak Gasparovic,

Rudjer Boskovic Institute, Croatia

Reviewed by:

Ryan Gimple,

Case Western Reserve University,

United States

Barbara Breznik,

National Institute of Biology

(NIB), Slovenia

*Correspondence:

Christophe Olivier

christophe.olivier@univ-nantes.fr orcid.org/0000-0002-9398-3215

Lisa Oliver

lisa.oliver@univ-nantes.fr orcid.org/0000-0002-5588-7564

Specialty section:

This article was submitted to

Cellular Biochemistry,

a section of the journal

Frontiers in Molecular Biosciences

Received: 23 October 2020

Accepted: 08 December 2020

Published: 27 January 2021

Citation:

Olivier C, Oliver L, Lalier $L$ and Vallette FM (2021) Drug Resistance in

Glioblastoma: The Two Faces of

Oxidative Stress.

Front. Mol. Biosci. 7:620677.

doi: 10.3389/fmolb.2020.620677
Glioblastomas (GBM) are the most common primary brain tumor with a median survival of 15 months. A population of cells with stem cell properties (glioblastoma stem cells, GSCs) drives the initiation and progression of GBM and is localized in specialized microenvironments which support their behavior. GBM are characterized as extremely resistant to therapy, resulting in tumor recurrence. Reactive oxygen species (ROS) control the cellular stability by influencing different signaling pathways. Normally, redox systems prevent cell oxidative damage; however, in gliomagenesis, the cellular redox mechanisms are highly impaired. Herein we review the dual nature of the redox status in drug resistance. ROS generation in tumor cells affects the cell cycle and is involved in tumor progression and drug resistance in GBM. However, excess ROS production has been found to induce cell death programs such as apoptosis and autophagy. Since GBM cells have a high metabolic rate and produce high levels of ROS, metabolic adaptation in these cells plays an essential role in resistance to oxidative stress-induced cell death. Finally, the microenvironment with the stromal components participates in the enhancement of the oxidative stress to promote tumor progression and drug resistance.

Keywords: glioblastoma, oxidative stress, drug resistance, tumor microenvironment, nutrition

\section{INTRODUCTION}

Glioblastoma (GBM, WHO classification IV grade) covers about $54 \%$ of all gliomas and $16 \%$ of total brain tumors (Louis et al., 2016). It is the most common primary brain tumor with an incidence of approximately three cases per 100,000 inhabitants in France. Its prognosis is bleak: the average survival is 15 months once the diagnosis is established (Ostrom et al., 2015), with $<10 \%$ of patients surviving 5 years after diagnosis. GBM is characterized by inter- and intratumoral heterogeneity, which has been suggested to contribute to resistance to treatment. As such, relapse may occur, in part due to a therapy-resistant subpopulation of GBM stem cells (GSCs) present or by the induction of dedifferentiation in the non-GSC subpopulation due to alterations in the REDOX state due to therapy (Bao et al., 2006; Diehn et al., 2009). The standard therapy follows the Stupp protocol (Stupp et al., 2005), which consists of tumor surgical resection followed by post-operative ionizing radiation (IR), comprising $60 \mathrm{~Gy} / 30$ fractions and concomitant plus adjuvant temozolomide (TMZ) chemotherapy. However, due to the infiltrating nature of GBM, complete removal of the tumor is not always possible. Chemotherapy and IR share common pathways to cell death, inducing DNA damage either directly or indirectly by generating reactive oxygen species (ROS). It is accepted that while low levels of ROS enhance cell growth and differentiation, higher levels induce cell death. Thus, in many cancers, the level of ROS is an important marker of the state of the tumor. 
Numerous studies have demonstrated the presence in GBM of a subpopulation of self-renewing and pluripotent GBM stemlike cells (GSCs) responsible for GBM formation, maintenance, invasiveness, and recurrence (Bao et al., 2006). Tomasetti et al. (2017) have shown that neural stem cells (NSCs) in the subventricular zone of the human brain might contribute to GBM formation and development, and Lee et al. (2018) have demonstrated that the somatic driver mutations in these NSCs have the ability to stimulate the development of the tumor. In addition, Chen et al. (2012) have identified a relatively quiet subpopulation of GBM cells, with properties similar to cancer stem cells that are the source of new tumor cells post-chemotherapy treatment and could be responsible for sustaining long-term tumor growth. A hierarchy in the stem cell population was likewise shown, and chemotherapy could assist in the expansion of pre-existing drug-resistant GSCs (Lan et al., 2017). Moreover, glial cells reside in a specific tumor microenvironment (TME), which supports tumor growth via direct contact and secretion. The TME participates in tumorigenesis by generating a ROS niche through oxidative stress (OS) (Schiffer et al., 2018). OS enhances cancer cell invasiveness but also supports GSC maintenance (Janiszewska et al., 2012) and thus participates in the evasion/resistance to treatment and consequently recurrence of the tumor (Burdon et al., 1990; Costa et al., 2014). Furthermore, another role of ROS in TME would be to influence, quantitatively and qualitatively, the nature of the infiltrating non-cancer cells in the tumor (Weinberg et al., 2019).

In this review, we will discuss the role of OS in radio- and chemotherapy in GBM. A listing of the activation of common cellular stress pathways, in particular with the production of ROS and engendering of metabolic reprogramming, is summarized in Figure 1. We will also discuss how the stress induced by the therapy regimes participates in the selection of GSCs and/or enhances the dedifferentiation of non-GSCs to GSCs caused by redox modifications. In addition, we will describe how, during gliomagenesis as well as during the local response to therapy, the TME contributes to stress and helps cancer cells escape through OS.

\section{OXIDATIVE STRESS AND CANCER}

Two different hypotheses described the effects of ROS in tumor cells, the first being "the threshold concept for cancer therapy," which states that as the amount of ROS in cancer cells increases, the ratio between ROS and the antioxidants is maintained in a well-controlled steady equilibrium, after which any further augmentation in ROS or reduction in antioxidants would result in cell death or increased sensitivity to therapy (Kong et al., 2000). The second hypothesis suggests that when both tumor and normal cells are subjected to comparable levels of exogenous ROS-producing agents, the intracellular ROS levels of tumor cells increase more readily than normal cells to attain a threshold and induce cell death (Wang and Yi, 2008). The changes induced during tumorigenesis are represented as changes in the redox status in tumor cells, generally activating the creation of ROS. These ROS molecules are typified as oxygen-carrying molecules that have reactive properties, consisting of radicals comprising $\mathrm{O}_{2}^{-}$(superoxide) and $\mathrm{HO}^{\bullet}$ (hydroxyl) as well as non-radicals such as $\mathrm{H}_{2} \mathrm{O}_{2}$ (hydrogen peroxide). ROS originate from oxygen, which is used in numerous metabolic reactions in organelles such as the mitochondria, endoplasmic reticulum (ER), and peroxisomes. On a physiological level, the action of ROS is to regulate signal transduction pathways and moderate the activity of mitochondrial enzymes and transcription factors. In cancer, the general consensus is that an elevated production of ROS would engender tumorigenesis by impeding DNA repair mechanisms, resulting in an accumulation in DNA damage, including base modifications, inter- and intra-strand binding, and DNA-protein bonds, as well as an increase in cell proliferation due to the increase in $\mathrm{H}_{2} \mathrm{O}_{2}$ and $\mathrm{O}_{2}^{-}$. Indeed OS can generate ROS-induced damage in proteins, lipids, and DNA, resulting in genomic instability. As such, cancer cells are constantly maintaining a balance between the response to OS and ROS production for their survival (Kong et al., 2000). The resilient cellular response to low oxygen concentrations under both physiological and pathological conditions involves varied pathways; the best known are the hypoxia-inducible factors (HIFs) and the ER stress responses. The HIF-related mechanisms respond to alterations in oxygen concentration that would influence the ability of GSCs to initiate tumors. Indeed GSCs respond to hypoxia, and an augmentation in the level of HIFs was detected in GSCs. Moreover, multiple HIF-regulated genes are selectively expressed in GSCs in comparison to other GBM cells (Li et al., 2009). Hypoxia has been shown to promote the self-renewal capacity of GSCs as well as the ability to promote a more stem-like phenotype in the non-stem cell population by the up-regulation of important stem cell factors including Oct4 or Nanog (Heddleston et al., 2009).

HIF-2 $\alpha$ is likewise expressed in GSCs at oxygen levels comparable to normal in vivo levels (2-5\%). Hence, in highly heterogeneous GBM tumors, different tumor cells survive in a wide spectrum of oxygen concentrations in their environment and, because of the levels of HIFs, generate a gain over normal cells by adapting to their surroundings. By consequence, the enrichment of ROS occurs, harming non-malignant cells and resulting in apoptosis, while tumor cells would survive and prosper in a hypoxic microenvironment.

\section{THE INTRACELLULAR SITES OF ROS GENESIS}

The main sources of ROS production in tumor cells include NADPH oxidases (NOXs) and the electron transport chain (ETC) in the mitochondria. Additionally, the ER also produces important amounts of ROS from oxidoreductases and NOXs. Both the mitochondrial ETC and NOXs decrease oxygen to the reactive superoxide anion $\left(\mathrm{O}_{2}^{-}\right)$, which undergoes a complex sequence of conversion reactions that result in the formation of hydrogen peroxide $\left(\mathrm{H}_{2} \mathrm{O}_{2}\right)$ as well as hydroxyl radical $\left({ }^{-} \mathrm{OH}\right)$ or reactive nitrogen species (RNS), including nitric oxide $\left(\mathrm{NO}^{-}\right)$. Besides the ETC, the mitochondria also contain enzymes that produce ROS. Some examples of mitochondrial enzymes 


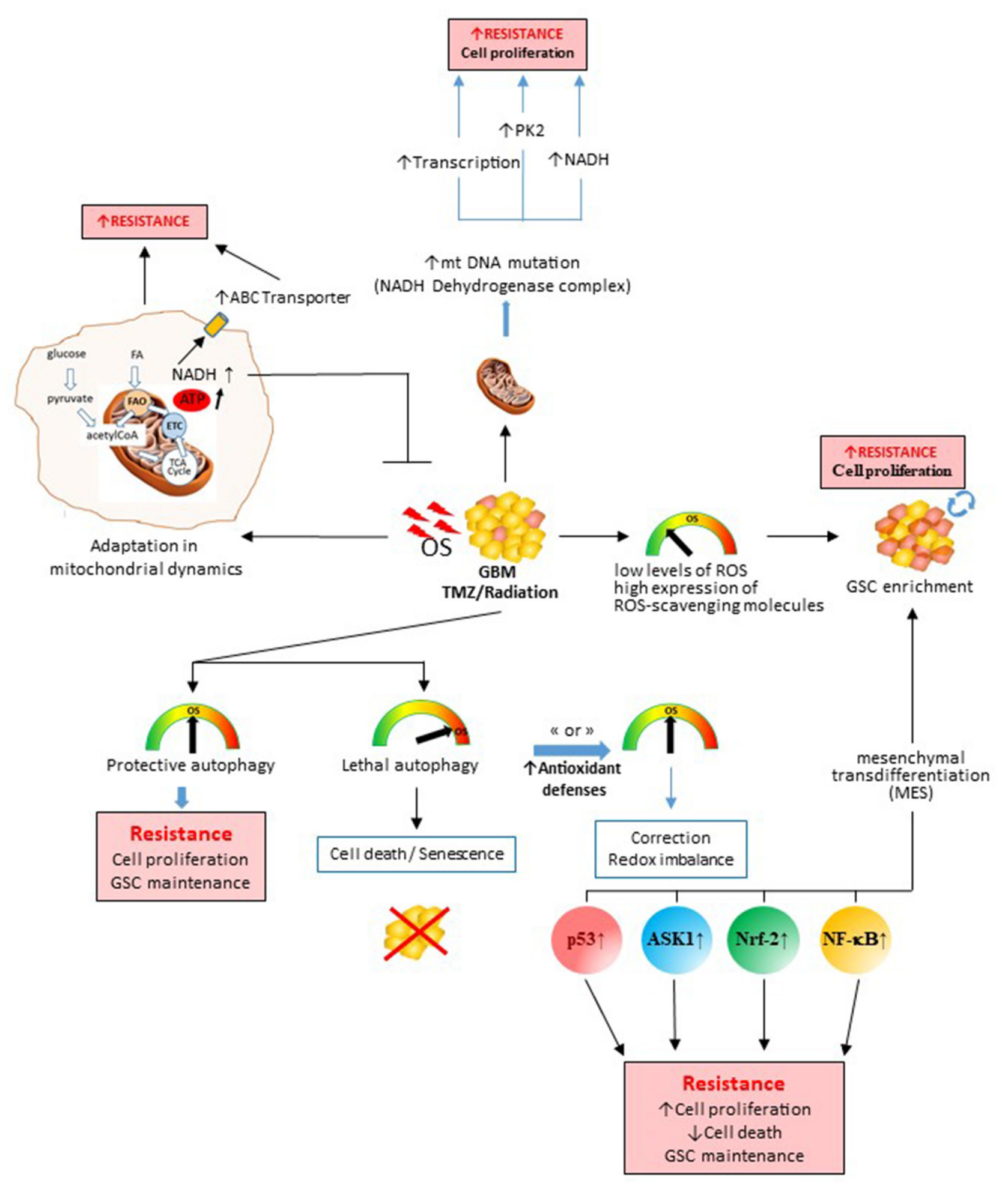

FIGURE 1 | Role of therapy-induced oxidative stress (OS) in the genesis of therapeutic resistance processes and tumor escape. OS induced by chemo- or radio-therapy during the treatment in glioblastomas will impact the survival/death balance, cell metabolism, glioblastoma stem cell subpopulation, and mitochondrial DNA. All these induced mechanisms will promote therapy escape and tumor recovery. Depending on the degree of stress induced and the antioxidant defenses activated, the cancer cell will either die or survive by different processes. ASK1, apoptosis signal-regulating kinase 1; NADH, reduced form nicotinamide adenine dinucleotide; NF-кB, nuclear factor kappa-light-chain-enhancer of activated B cells; Nrf-2, nuclear factor erythroid-2-related factor 2; PK-2, pyruvate kinase. 
that produce ROS are the inner mitochondrial membrane dihydroorotate dehydrogenase that is coupled to complex III of the respiratory chain and generates $\mathrm{O}_{2}^{-}$and $\mathrm{H}_{2} \mathrm{O}_{2}$, glycerol-3phosphate dehydrogenase 2 (GPDH-2), which produces ROS via the reverse electron transport from flavin adenine dinucleotide (FAD) to the electron transfer chain, and the outer mitochondrial membrane monoamine oxidase (MAO) that releases ROS through the deamination of serotonin to catecholamine. About $2 \%$ oxygen is used by the mitochondria to generate $\mathrm{O}_{2}^{-}$, and thus this organelle is considered as the main source of ROS and this through multiple pathways (Murphy, 2009). As stated previously, the ER is another organelle that participates in ROS production in the cell and encompasses two important sources of ROS: the first is NOX4, a member of the NADPH oxidase family, and the second is the Erol $\alpha$-PD-I protein-folding pathway. Thiol-disulfide exchange reactions between the catalytically active domains of PD-I and cysteines of nascent client proteins could result in rupture, creation, or isomerization of disulfide bonds. This oxidoreductase reaction necessitates the activity of the membrane-bound ER oxidoreductin $1 \alpha$ (Ero- $1 \alpha)$, a FADdependent oxidoreductase. A derivative of this Ero- $1 \alpha-\mathrm{PD}-\mathrm{I}$ oxidative protein folding pathway is $\mathrm{H}_{2} \mathrm{O}_{2}$, which would enhance the oxidative environment in the $\mathrm{ER}$, which is characterized by a high glutathione disulfide-to-glutathione (GSH) ratio. The folding of oxidative proteins involves quiescin-sulfhydryl oxidase 1 (QSOX-1) that produces $\mathrm{H}_{2} \mathrm{O}_{2}$ and contributes in the creation of disulfide bonds in proteins.

\section{BYPASSING MECHANISMS OF CHEMO- AND RADIO-RESISTANCE IN GLIOBLASTOMA}

Morphologically, GBM tumors contain chronic hypoxic regions (Rong et al., 2006; Matschke et al., 2016), with a naturally high resistance to treatment due to an augmentation in hypoxiainducible factor-1 alpha (HIF-1 $\alpha$ ) (Hsieh et al., 2012). In these regions, the concentration of $\mathrm{H}^{+}$increases with distance from the blood vessels due to the distance of diffusion and the increased production of lactate from anaerobic cells, creating a highly acidic region (Fang et al., 2008), which is also linked to radio-resistance (Raghunand and Gillies, 2000; Hirschhaeuser et al., 2011), while lactate would act as an antioxidant by scavenging $\mathrm{O}_{2}^{--}$and $\mathrm{OH}^{-}$, thereby inhibiting lipid peroxidation (Groussard et al., 2000). In these regions, dormant cells and hypoxic cells have gene profiles distinct from cells found in well-vascularized regions, which is associated with a lower drug sensitivity (Lu et al., 2010). A subpopulation of GSCs resides in these hypoxic niches far from blood vessels due to their ability to adapt to the low $\mathrm{O}_{2}$ microenvironment (Ito and Suda, 2014). Consequently, structural tumor hypoxia or a hypoxic necrotic region contributes to tolerance to ROSinducing treatments and plays an important role in therapy resistance, aggressiveness, and relapse (Vaupel and Mayer, 2007; Sattler et al., 2010). Several other mechanisms could contribute to therapy resistance, including a paradoxical increase in mitochondrial ROS production during hypoxia through a HIF-1 regulation loop (Murphy, 2009).

Brain tumors have a distorted redox homeostasis, resulting in the stimulation of survival pathways that would facilitate tumor growth and resistance. The current treatment is based on surgical excision associated with the combination of radio- and chemotherapy, but tumor recurrence remains constant with the acquisition of resistance by activation of several systems, some of which modify the redox equilibrium. Relapse occurs in part due to the redox-induced dedifferentiation of non-GSCs that would add to this therapy resistance (Bao et al., 2006; Diehn et al., 2009).

Quite a few other mechanisms could be responsible, including OS, which would modulate the efficacy of treatments and resistance in various ways, impacting on drug sensitivity, apoptosis, angiogenesis, or inflammatory pathways (Nathan and Cunningham-Bussel, 2013). GBM therapies induce the activation of redox-sensitive transcription factors, including nuclear factor- $\kappa \mathrm{B}(\mathrm{NF}-\kappa \mathrm{B})$, nuclear factor erythroid 2 p45-related factor 2 (Nrf-2), or HIF-1 that would up-regulate cell survival molecules belonging to the BCL-2 family of proteins and the Akt survival pathway.

It has been shown that, during chemotherapy, tumor cells could overcome drug-induced OS by enhancing their antioxidant systems as well as an increasing P-gp pump efflux to acquire a new redox balance due the increased ROS accumulation and antioxidant systems in a process of redox rearranging (see Figure 1). This adjustment to OS would result in low levels of mitochondrial ROS, increased mitochondrial respiration, and resistance to chemotherapy (Oliva et al., 2011). Redox reactions initiated by therapy induce significant changes in cells, pathways regulating survival, and inflammation, as well as induce an up-regulation of antioxidant enzymes, thereby promoting conformational changes in the drug transporters. The redox status of the cell has a large effect on disulfide bond formation, protein folding, and dimerization of multidrug resistance (MDR) proteins such as MDR-1 (Liu et al., 2016), thereby increasing drug resistance (Tivnan et al., 2015).

IR likewise causes charged particles (electrons or ions) to traverse the cell and directly ionize DNA, causing doublestrand breaks (DSB), which could be restored by homologous recombination (HR) and non-homologous end joining (NHEJ) mechanisms, or a base damage and single-strand breaks (SSB) repaired by BER and SSB repair mechanisms, respectively (Maier et al., 2016). The principal consequence of ionizing radiation is the elimination of cells predominantly by the induction of DNA damage, resulting in a diminution of cell population and a consequent functional deficiency. Radiation-induced DSB characterize the most deadly form of DNA damage, resulting in cell death if not repaired (Vlashi et al., 2011; Lan et al., 2012). Radiotherapy, associated with chemotherapy in GBM, also acts indirectly, producing free radicals that are derived from the ionization or excitation of the water constituent of the cells, resulting in the formation of aqueous free radicals and ROS, including $\mathrm{O}_{2}^{--}$and $\mathrm{H}_{2} \mathrm{O}_{2}$. However, these radicals are less significant than $\mathrm{OH}^{\circ}$ in producing the fatal DNA damage (Agostinelli and Seiler, 2006). Free radicals activate cell death pathways, with the production of ROS leading to 
massive OS, DNA damage, alterations in mitochondrial function, stem cell enrichment (Vlashi et al., 2011; Lan et al., 2012), and modifications in radio- and chemo-sensitivity (Ke et al., 2014). The adaption of tumor cells to survive could rise from cellular reprogramming (Lagadec et al., 2012) and/or the dedifferentiation of certain tumor cells to more pluripotent states, along with GSC selection among tumor cells.

During tumorigenesis, the microenvironment is in continual transition with alteration in hypoxia, nutrients, and changes in acidic stress; the result of which is that cells have to continually modify their metabolic pathways (Vander Heiden and DeBerardinis, 2017). This metabolic stress promotes the emergence of CSCs. Under normoxic conditions, glucose provides acetyl-CoA, which condenses with oxaloacetate to form citrate. Glutamine would participate in this production via $\alpha$ ketogluterate. Under hypoxia or glucose deprivation, glutamine would become the major source of citrate, and tumor cells would be able to maintain cell proliferation despite a marked reduction in citrate production from glucose. Two types of GSCs are present in GBM; the first are highly proliferative cells found in the perivascular zone, and the second group is composed of quiescent cells found in the hypoxic regions, suggesting that the microenvironment could influence the metabolism of these cells (Brooks and Parrinello, 2017). GSCs depend on glycolysis to a lesser degree than more differentiated tumor cells (Vlashi et al., 2011). In addition, glycolysis was demonstrated to be greater in mesenchymal GSCs than in proneural GSCs, suggesting a correlation between the metabolism in GSCs and the tumor subtype (Mao et al., 2013). This could be due to the overexpression of the aldehyde dehydrogenase (ALDH) family of genes, especially ALDH1A3 that was markedly increased in mesenchymal GSCs (Mao et al., 2013). Furthermore, Shibao et al. have shown that the heterogeneous metabolism in GSCs could be due to environmental factors. There seems to be plasticity in the metabolism of GSCs, with a reversible switch between glycolysis and oxidative phosphorylation depending on the availability of oxygen and, as such, influenced by hypoxia. There appears to be a dichotomy suggesting that more glycolytic GSCs are found in hypoxic niches, while GSCs having an oxidative phosphorylation metabolism were found to be more in the perivascular regions (Shibao et al., 2018). Higher mitochondrial activity in GSCs would result to an increase in ROS concentrations. Furthermore, PRDX4 negatively regulates OS levels in order to protect GSCs from cell death and increase resistance to treatment (Kim et al., 2014). It has been shown that TRAP1 modified mitochondrial respiration and reprogrammed cellular metabolism (Yoshida et al., 2013). Park et al. (2019) demonstrated that an interaction in GSCs between the mitochondrial chaperone TNF receptorassociated protein 1 (TRAP1) and the major mitochondrial deacetylase sirtuin-3 (SIRT-3) improved the deacetylase activity of SIRT-3 and consequently reduced ROS production by SOD-2, the deacetylation activity of which increased. Finally, the increase in the mitochondrial respiratory capacity and the reduction in ROS production would aid GSCs to adapt to stress, thereby resisting cell death (Park et al., 2019). This distinction is reinforced by the data of Jin X. et al. (2017), which demonstrated that the vascular regions in GBM showed a proneural phenotype and would contain GSC-activated EZH2, while the hypoxic regions showed a mesenchymal profile with GSCs expressing BMI1. Both BMI1 and EZH2 promoted cell survival under stress, and EZH2 contributes to resistance to radiation and chemotherapy, suggesting that both BMI1 and EZH2 may allow plasticity of the state under environment conditions.

\section{THE PATHWAYS OF RESISTANCE TO RADIO- AND CHEMOTHERAPY AND PRODUCTION OF ROS ARE INTERCONNECTED TO ENSURE SURVIVAL}

IR initiates alterations in oxidative phosphorylation, which would augment the glycolytic rate that is linked to radio-resistance. An increase in ROS would induce HIF- $1 \alpha$ stabilization (Dewhirst et al., 2008) and pyruvate dehydrogenase kinase 1 (PDK-1) (Rademakers et al., 2008) that would act to limit the entry of pyruvate into the Krebs cycle, thereby decreasing mitochondrial oxygen consumption (Papandreou et al., 2006).

It has also been shown that human biliverdin reductase, which converts biliverdin to bilirubin, a potent antioxidant responsible for the maintenance of intracellular redox homeostasis (Sedlak and Snyder, 2004), was induced by OS associated with hypoxia and ROS induced during TMZ treatment (Kim et al., 2013). GBM radio-resistance is linked to mitochondrial modifications and an unusually high production of ROS scavengers. An increase in mitochondrial $\mathrm{H}_{2} \mathrm{O}_{2}$ induces survival mechanisms with an up-regulation of catalase and mitochondrial superoxide dismutase (SOD-2) (Lee et al., 2004). An elevated activity of the latter enzymes and an increase in the level of reduced glutathione (GSH) are associated with the acquisition of resistance (Trachootham et al., 2009; Ortega et al., 2011). The interconnection of the consequences of the two types of therapeutic strategies is illustrated by the fact that GSH can form glutathione S-conjugated molecules to enable drug efflux by MRP-1 (Krause et al., 2007), and higher concentrations of GSH result in elevated chemotherapeutic resistance in numerous cancers (Traverso et al., 2013). TMZ is an alkylating agent, which functions by methylating guanine in the DNA at the O6 position, preventing a match with thymine in the replication cycle (Jiang et al., 2012). TMZ induced DNA damage and the production of ROS (Lo Dico et al., 2019), but the efficiency is very relative since nine patients out of 10 relapsed (Stupp et al., 2009). TMZ resistance is under the control of the DNA repair enzyme, O6-methylguanine-DNA methyl-transferase (MGMT). The expression of MGMT is silenced by methylation in the promoter region of the gene in half of all GBM patients (Hegi et al., 2004). Rocha et al. (2016) showed that TMZ resistance and recurrence are associated to OS. Besides its alkylating effect, TMZ has other cellular functions, including cell death, carried out by increasing the level of ROS (Zhang et al., 2010) and controlling autophagy (Yan et al., 2016), apoptosis (Roos et al., 2007), and HIF- $1 \alpha$ activity (Lo Dico et al., 2018). There is a close relationship between autophagy and TMZ resistance since TMZ toxicity depends on both (i) the chaperone protein 
folding function and (ii) the augmentation of protein degradation pathways, both of which are mediated by the ER and autophagy (Lo Dico et al., 2019).

Chang et al. (2017a) showed that specificity protein-1 (Sp1), a nuclear transcription factor, protects GBM cells against stress and TMZ-induced death. Sp1 has been shown to up-regulate antioxidant genes, especially those that are beneficial against stress-induced cellular damage (Yeh et al., 2011; Chang et al., 2017a). Poschmann et al. (2015) linked the peroxiredoxin1 (PRX-1) status in glioma to OS caused by therapy and showed that a decreased level of PRX-1 was associated with a better response to chemotherapy (Dittmann et al., 2012). It was hypothesized that PRX-1 (Svendsen et al., 2011) and thioredoxin (TRX) (Saitoh et al., 1998), when bound to apoptosis signalregulating kinase 1 (ASK1), inhibited their phosphorylation and the subsequent activation of the cell death pathways that follow their dissociation under OS. As such, the overexpression of PRX-1 generated by therapy in GBM, serves as a survival factor and protects against therapy-induced stress (Svendsen et al., 2011). The level of expression of peroxiredoxin-2 (PRX2) correlated with the resistance to radio- or chemotherapy in GBM (Park et al., 2000) and the overexpression of TRX, particularly in the hypoxic region of tumors, contributing to chemotherapy resistance, which was negatively regulated by TRX-interacting protein (TXNIP) (Haas et al., 2018). The TXNIP level is directly correlated with patient survival in GBM (Zhang et al., 2017), and increasing levels of TRX-1 escalate the scavenging of ROS generated by various anticancer agents (Marks, 2006). In the brain, GSH and GSH-related enzymes, glutathione peroxidase (Gpx1), are essential for the elimination of ROS and detoxification (Traverso et al., 2013). Zhu et al. (2018) demonstrated that TMZ-resistant glioma cells have higher levels of glutathione reductase (GR) and GSH than TMZ-sensitive cells. Dalavaikodihalli Nanjaiah et al. (2019) showed that GSH, GR, and catalase were all up up-regulated through the glutamatemediated activation of $\mathrm{N}$-methyl-D-aspartate receptor. The expression of the amino acid antiporter that mediates the exchange of extracellular cysteine and intracellular glutamate across the plasma membrane, the system $\mathrm{xc}^{-}$, was found to be elevated in GBM cell lines, increase GSH production, mitochondrial biogenesis, oxidative phosphorylation, and ATP generation (Polewski et al., 2016), and conferred resistance to OS while decreasing sensitivity to TMZ.

\section{ROS PRODUCTION AND INFLAMMATION}

Inflammation induced by GBM therapies participates in the activation of tumor cell death processes through the production of ROS, with different pathways counteracting the effects of chemo- and radiotherapy. These pathways include Nrf-2/Kelchlike ECH-associated protein 1 (Keap1), mitogen-activated protein kinases (MAPKs), nuclear factor kappa B (NF-кB), protein kinase $C(\mathrm{PKC})$, signal transducers and activators of transcription-3 (stat-3), and peroxisome proliferator-activated receptor- $\gamma(\operatorname{PPAR} \gamma)$, which regulate the antioxidant defense systems (Jaramillo and Zhang, 2013). Indeed ROS, OS pathways, and inflammation are all closely linked and participate in the resistance to therapy. ROS and RNS production is central to the progression of inflammation (Mittal et al., 2014). ROS acts as both a signaling molecule and a mediator of inflammation (Conti et al., 2010). Depending on the level of ROS induced and the initial resistance capacity of tumor cells, the associated inflammation can have an important impact on the fate of the cell. The NF- $\kappa \mathrm{B}$ a key regulator of inflammatory gene expression (Conti et al., 2007) has been shown to stimulate, via transcription, genes encoding pro-inflammatory cytokines (IL-6), cell adhesion molecules, inducible nitric oxide synthase or iNOS (NOS2), and cyclooxygenase-2 (COX-2) (Grivennikov et al., 2010) and, together with $\mathrm{NO}$ derived from iNOS and $\mathrm{PGE}_{2}$, has key functions in the pathogenesis of inflammation and carcinogenesis (Nagai et al., 2002). The connection between NF- $\mathrm{BB}$ signaling and ROS is complex. Depending on the circumstances, ROS can either activate or inhibit NF- $\mathrm{BB}$ signaling and, as such, interact with NF- $\kappa \mathrm{B}$ signaling pathways in many ways. NF- $\kappa \mathrm{B}$ activity is regulated by the expression of ROS and NF- $\kappa \mathrm{B}$-dependent genes that affect the concentration of ROS in the cell (Morgan and $\mathrm{Liu}, 2011)$. NF- $\mathrm{\kappa B}$ activation can also contribute to the protection against high levels of ROS produced during therapy by positively regulating manganese SOD-2 (Djavaheri-Mergny et al., 2004; Dhar and St Clair, 2012), copper-zinc superoxide dismutase (Rojo et al., 2004), ferritin heavy chain (Pham et al., 2004), TRX1 and TRX-2 (Djavaheri-Mergny et al., 2004; Kairisalo et al., 2007), glutathione S-transferase $\pi$ (GST- $\pi$ ), and glutathione peroxidase-1 (Gpx1) (Schreiber et al., 2006) in response to OS (and hypoxia). Heme oxygenase (HO-1) is also up-regulated by NF- $\kappa B$ (Lin et al., 2007).

However, enzymes that stimulate the production of ROS and their targets are all up-regulated, including NADPH oxidase (NOX-2) (Anrather et al., 2006) and xanthine oxidoreductase (XOR), which are regulated by NF-кB (Xu et al., 1996), iNOS and NOS1 (Nishiya et al., 2000), COX-2, and prostaglandin G/H synthase 2 (Annabi et al., 2009). The latter plays a key role in inflammation (Smith et al., 1996) and COX-2 by stimulating the release of pro-angiogenic prostaglandins (Tsujii et al., 1998), acting on tumorigenesis and tumor growth. Annabi et al. (2009) showed an enhanced COX-2 expression in the CD133+ GSC population.

With the induction of inflammation, there is an augmentation in Il-6 production, which would constitute a pro-survival signal in GBM (Van Meir et al., 1990) and particularly in GSCs, which preferentially express the IL-6 receptor alpha (IL-6R $\alpha$ ) and glycoprotein 130 (gp-130), generating the heterodimerization of receptors and culminating in the activation of stat- 3 signaling (Wang et al., 2009). Tamari et al. (2017) explored the control of ROS by IL-6 in radio-resistance in GBM cell lines and showed that IL-6 was implicated in the inhibition of mitochondrial ROS $\left(\mathrm{O}^{--}\right)$and intracellular $\mathrm{ROS}\left(\mathrm{OH}, \mathrm{ONOO}^{-}\right)$. stat-3 has also been demonstrated to be a central element linking extracellular signals to transcriptional pathways involved in proliferation and cell cycle progression (Brantley and Benveniste, 2008).

During therapy in GBM, stress, inflammation, and pro-apoptotic signals could also lead to the activation of the Nrf-2 pathway. Nrf-2 maintains redox homeostasis (Ma, 
2013) and is an essential antioxidant transcription factor regulator in cells against xenobiotics capable of triggering DNA damage and initiating carcinogenesis (Kensler et al., 2007). However, the role of Nrf-2 in drug resistance was suggested by its action to induce antioxidant enzymes (Wang et al., 2008). Indeed elevated levels of ROS (during radio- or chemotherapy) induced the translocation of Nrf-2 to the nucleus, where it bound to the antioxidant response element (ARE) or the electrophile-response element in the promoter region of Nrf-2, targeting antioxidant and anti-apoptotic genes, including heme-oxygenase 1 (HO-1) (Pan et al., 2013; Tebay et al., 2015), which catalyzes heme degradation and the production of carbon monoxide (CO), ferrous iron $\left(\mathrm{Fe}^{2+}\right.$ ), and biliverdin (Kim et al., 2013). HO-1 plays a protective role in chemo-resistance through the induction of autophagy MAPK kinase pathways and protection against ROS damage to increase the resistance to therapy (Johnson, 2015). The shift between activation and inactivation of Nrf-2 protects GBM cells from the deleterious effects of ROS in cells produced by therapy, thereby preventing apoptosis and sustaining cell survival (Ma, 2013). It has been shown also to support tumorigenesis in primary cultures of GBM cells by promoting proliferation and resistance to cell death programs such as ferroptosis (Fan et al., 2017). Nrf-2 plays a transcriptional regulatory role on the ECM remodeling marker MMP-2, favoring chemo-resistance (Rajesh et al., 2019).

The translocation of Nrf-2 to the nucleus caused by OS has been shown to activate the glutamate cysteine ligase modifier subunit, glutathione S-transferase $\pi$, GSH availability and use, glutathione reductase, and glutathione peroxidase (Sporn and Liby, 2012; Rocha et al., 2016). Besides the Nrf-2 pathway, other highly efficient antioxidant defense systems, the PRXs, have a key function in the preservation of cellular redox homeostasis, preventing the oxidation and aggregation of proteins. PRXs are activated during therapy and, as such, play an essential role in therapy resistance (Sharapov and Novoselov, 2019).

\section{ROS AND AUTOPHAGY}

Numerous studies have shown that TMZ could induce autophagic cell death in GBM cell lines that were under the control of Nrf-2 (Kanzawa et al., 2004; Stepkowski and Kruszewski, 2011; Zhou et al., 2013). The induction of stress by therapy could affect tumor cells in different ways: including the induction of autophagy, cellular senescence, apoptosis, or necrosis, all of which are, in part, interconnected, and damages induced by therapy-either chemo- or radiotherapy could induce autophagy as a housekeeping process (Kanzawa et al., 2004; Lin et al., 2012). Autophagy could also prevent the initiation of tumorigenesis or, inversely, autophagy could support gliomagenesis by increasing cancer cell survival under unfavorable conditions. Glioma cells can escape to stressinduced effects with autophagy to survive some therapies (Kim et al., 2017). However, this process is complex because massive autophagy can induce lethal "self-eating" and apoptosis ( $\mathrm{Li}$ et al., 2011). Autophagy, which induces the degradation and recycling of long-lived proteins or organelles, can be directed by ROS and so with being indirectly regulated by antioxidant systems. Autophagy is an essential event in GBM resistance to treatment and presents a double face.

Several pathways are associated with its activation in GBM cells; the extracellular signal-regulated kinase1/2 (ERK1/2) pathway (Scherz-Shouval et al., 2007), class I phosphatidylinositol 3-phosphate kinase (PI3K)/AKT/mammalian target of rapamycin (mTOR) pathway (Fan et al., 2010), and nuclear factor kappa-B (NF-кB) pathway. The redox imbalance has an essential role in the process, with the mitochondria as the main source of ROS in autophagy signaling. Through these pathways, dual effects of TMZ on autophagy exist, depending on the concentration. Both autophagy inducing death and protective autophagy can be achieved, and this would affect tumor cell death, GSC differentiation, or resistance to treatment (Buccarelli et al., 2018; Feng et al., 2019).

It has been suggested that, during induced stress, there is a simultaneous activation of autophagy/mitophagy and apoptosis (Kubli and Gustafsson, 2012). Mitophagy, a selective autophagic process, is normally an onco-suppressor process that prevents oncogenic transformation (Wang and Klionsky, 2011). During cancer cell survival under cytotoxic stress, these stresses could induce damage in the mitochondria, resulting in the removal of the damaged mitochondria from the cell by mitophagy and thereby reducing mitochondrial ROS. If mitochondrial damage is not repaired and mitophagy is inactivated, the apoptotic pathway would be activated, resulting in cell death (Kubli and Gustafsson, 2012). However, transfer of the mitochondria between cancerassociated fibroblasts and a GBM tumor cell subpopulation could help cells to escape to this process (Salaud et al., 2020).

\section{IMPACT OF ROS AND GLIOBLASTOMA STEM CELLS}

OS or other stresses such as hypoxia result in the enrichment of GSCs (Pistollato et al., 2010). GSCs have a radio- and chemo-resistant phenotype responsible for the constant relapse (Liu et al., 2015), in part because of the high expression of anti-apoptotic proteins and drug efflux transporters (Nakai et al., 2009) and the constitutive activation of the DNA repair element, poly-ADP-ribose polymerase 1. MacLeod et al. (2019) explored the mechanisms of TMZ sensitivity in GSCs and confirmed the implication of key members of the mismatch repair (MMR) pathway, including MutL homolog 1 (MLH1), MutS protein homolog-2 and-6 (MSH-2 and MSH-6), and the MMR endonuclease PMS2, which plays an important role in mediating oxidative DNA damage repair (Brierley and Martin, 2013). The DNA replication licensing factors MCM-8 and MCM9, which together form a dimeric helicase complex, are likewise involved in homologous recombination with the zinc finger $\mathrm{CCCH}$ domain-containing protein $7 \mathrm{~A}, \mathrm{ZC} 3 \mathrm{H} 7 \mathrm{~A}$, the inactivation of which results in an increased sensitivity to oxidative DNA damage repair (MacLeod et al., 2019). This resistance can be attributed, among others, to the detoxification mechanisms of $\mathrm{O}^{--}$and NO formation and enhanced autophagy (Lyakhovich and Lleonart, 2016). Baulch et al. (2016) demonstrated that OS 
induced by radiation in primary GBM cell cultures resulted in the secretion of extracellular vesicles (EVs) that induced cellular reprogramming to induce pluripotency and were amplified with repeated irradiations. Similarly, mesenchymal transdifferentiation and radio-resistance in GSCs could be triggered by the activation of NF-kB (Bhat et al., 2013). Resistance to therapy and tumor recurrence are amplified by the ROSinduced Nrf-2 activity and the consequential maintenance of GSC self-renewal and proliferation that would result in tumor relapse (Zhu et al., 2013) and inhibition of GSC differentiation (Zhu et al., 2014).

The expression of stemness markers has been shown to increase with inflammation, hypoxia, or radio- and chemotherapy (Hsieh et al., 2015). The $\mathrm{CD}_{133^{+}}$and Bmi-1 proteins associated with stem cells and drug resistance are linked to increased SOD-2 expression (Siddique and Saleem, 2012). SOD-2 overexpression in GSCs reduces the O ${ }^{--}$reaction and caspase-dependent apoptosis, culminating in the acquisition of TMZ resistance (Chien et al., 2019). Sp1, which modulates SOD2, contributes to the tolerance of TMZ in GBM cells (Chang et al., 2017a,b). Sp1 also promotes p53-induced glycolysis regulatory phosphatase expression in GBM by decreasing OS in cells through the pentose phosphate pathway-mediated NADPH generation, an important ROS scavenger in cells (Tang and $\mathrm{He}, 2019$ ).

Additionally, IR augmented the transdifferentiation of GBM cells, in particular, that of GSCs into vascular endothelial cells (Soda et al., 2011; Deshors et al., 2019) that resulted in improved neovascularization in GBM tumor and thus participated indirectly to patient relapse. Furthermore, $\mathrm{H}_{2} \mathrm{O}_{2}$ induced OS selectively increased miR-34a (Baker et al., 2016), which also triggered the transdifferentiation of GSCs into vascular endothelial cells (Jin Z. et al., 2017). SOX-2 and stat3 have been shown as modulators of these actions (Smith and Macleod, 2019). In this context, radio- and chemo-resistant GSCs present a metabolic adaptation presenting a reduced glucose dependence, an improved lipid catabolism, ROS, mitogenactivated protein kinases (MAPKs) activity, and $\mathrm{NAD}^{+}$level, and an amplified SIRT1/PGC1 axis that promotes autophagy, resulting in an increase in the maintenance and repair machinery (Ye et al., 2013).

\section{ROS AND TUMOR MICROENVIRONMENT}

It has been suggested that stress stimuli from the microenvironment maintain the GSC subpopulation, which has a high level of drug resistance. Microenvironment is, in fact, essential for tumorigenesis and dysregulation of redox equilibrium.

The tumor microenvironment represents non-tumor cells within the tumor, which include the inflammatory infiltrate predominantly of microglia and macrophages, tumor-infiltrating lymphocytes, neutrophils, normal and reactive astrocytes, cancer-associated fibroblasts (CAFs), endothelial cells, and vascular pericytes (Bissell and Radisky, 2001; Tlsty and Coussens, 2006). The TME also contains proteins and non-protein biomolecules (polysaccharides, hormones, NO, etc.) that make up the extracellular matrix (ECM). The TME is principally perceived and confirmed in niches, however, it plays an important role in regulating everything in the tumor and in the surrounding tissue (Schiffer et al., 2018). Indeed, interactions between the tumor cells, ECM, soluble factors and blood vessels generate an intricate diverse environment that is in continual transformation supporting and maintaining tumorigenesis (Greaves and Maley, 2012). The metabolism of the different cells present in the TME, cell-cell interactions, the remodeling of ECM proteins to form the structure of the TME and the blood supply, give raise to several structural environmental factors such as hypoxia $\left(\mathrm{O}_{2}\right.$ tension varying from 0.1 to $3 \%$ ), acidity and alterations in the composition of the ECM and the accretion of soluble factors including $\mathrm{O}_{2}$, nutrients, ROS, RNS, ATP, $\mathrm{Ca}^{2+}, \mathrm{H}^{+}$, growth factors, chemokines and cytokines (Frisch et al., 2019). All these factors have an effect on the metabolism of cells and therefore, on the function of the cells, thus the TME is constantly fluctuating and plays a critical role in drug resistance, angiogenesis, cell death, DNA repair, OS, immune escape, the level and activity of multidrug resistance (MDR)-related genes, tumor progression, and epithelial-tomesenchymal transition (Zhang et al., 2020). As such, the TME represents a key factor in defining and regulating the preservation of tumor heterogeneity, tumor progression, and drug resistance (Da Ros et al., 2018). The principal function of the relationship between tumor cells and TME in tumorigenesis has been said to be the dynamic collaboration between the two to stimulate the proliferation and protection of the tumor cells from immune surveillance and radio- and chemotherapy. Indeed it has been shown that most of the non-tumor cells present in the TME assume a tumor-promoting phenotype subsequent to alterations by the local environment on their cell functions, which include changes in gene expression.

ROS also affect cells that constitute the TME. OS in the TME is one of the main factors that mediate the conversion of cell types, such as normal fibroblasts and mesenchymal stem cells to CAFs, which play a key role in tumor cell proliferation, survival, angiogenesis, invasion, inflammation, and ECM remodeling via cross-talk with cancer cells through paracrine signals (Costa et al., 2014; Salaud et al., 2020). In addition to regulating the conversion of fibroblasts to CAFs, the oxidative TME can also increase the production of paracrine signals and matrix remodeling enzymes that would promote the invasion and metastasis of tumor cells. The regulation of protein tyrosine phosphatases (PTPases) by ROS appears as a key mechanism capable of regulating signaling by cell surface receptors, including tyrosine kinase receptors and integrins. For instance, an increase in ROS by CAFs causes the secretion of pro-invasive signals, including HGF, IL-6, VEGF, CXCL-12, and CXCL-14. ROS activation of the CXCL-12/CXCR4 signaling pathway contributes to a cross-talk between tumor cells and CAFs (Orimo et al., 2005). For example, the cytokine CXCL-12 is secreted by CAFs, while its receptor CXCR-4 is found mainly on tumor cells. Thus, CXCL-12 signaling by receptor CXCR-4 requires an intimate interaction between CAFs and tumor cells, which would result in the proliferation of 
tumor cells as well as acceleration of neo-angiogenesis due to the recruitment of endothelial progenitor cells (Costa et al., 2014). Thus, chemokines released by non-tumor cells can act as paracrine factors, creating a communication with tumor cells to promote tumorigenesis (Coppé et al., 2010; Fiaschi and Chiarugi, 2012). CAFs and/or cancer-associated macrophages (CAMs) collaborate together to engender a pro-oxidant environment. Due to the activation of NOS2, CAMs can actively fabricate ROS, which will instigate the recruitment of CAFs and the activation of MMPs (Giannoni et al., 2012). The chemo-attractant, stromalderived factor- $1 \alpha$ (SDF-1 $\alpha) /$ hemokine (C-X-C motif) ligand 12 (CXCL-12), the C-X-C receptor type 4 (CXCR-4), and the cysteine protease cathepsin $\mathrm{K}$ (cat $\mathrm{K}$ ) are localized to GSC niches in GBM (Hira et al., 2015) and SDF-1 $\alpha$ acting through its interactions with CXCR-4 and/or its second receptor CXCR-7 on GSCs facilitates the homing of GSCs to niches, while cat K, which is up-regulated by $\mathrm{ROS}\left(\mathrm{H}_{2} \mathrm{O}_{2}\right)$ (Tsai et al., 2014), can cleave and thereby inactivate SDF- $1 \alpha$ and, in doing so, facilitate the migration of GSCs out of the niches.

MDSC, Treg, and CAM provide an immunosuppressive environment that would contribute to tumor cell proliferation, invasion, and resistance to chemotherapy (Badie and Schartner, 2000; Beier et al., 2012; Hira et al., 2017). $\mathrm{CD}^{+} \mathrm{T}$ cells are crucial for the anticancer immune response in tumors; however, the immunosuppressive environment formed in the TME would ultimately result in the suppression of the cytotoxic $\mathrm{T}$ lymphocyte response, culminating in cancer progression. Inflammatory cells support tumor growth, invasion, and therapy resistance instigated by the secretion of specific molecules and factors that favor the anti-inflammatory activity (TGF-B, ARG1, and IL-10), tissue remodeling, and angiogenesis (VEGF, MMP2, MMP9) (Grivennikov et al., 2010). Furthermore, the effect of inflammatory cells on the ECM to release MMP would directly affect GSCs. High levels of ROS are major factors in immunesuppression and inhibition for $\mathrm{T}$ cell activation and proliferation, while low levels of ROS generate $\mathrm{T}$ cell activation in the TME, whereas CAFs have been implicated in immune-suppression of $\mathrm{CD}^{+} \mathrm{T}$ cells in GBM. Ford et al. (2020) have shown that the pharmacologic inhibition of NADPH oxidase 4 in the proneural subtype of GBM "normalized" CAFs to a quiescent phenotype, resulting in intratumoral $\mathrm{CD}^{+} \mathrm{T}$ cell infiltration and thereby overcoming the CAF-mediated $\mathrm{CD}^{+}{ }^{+} \mathrm{T}$-cell exclusion effect. CAFs or CAMs would together synergize to generate a prooxidant environment.

The redox landscape extends beyond the single cell to the TME. Moreover, the TME is associated with a reduced oxygen concentration, initiating a hypoxic environment that is linked to an amplified tumoral aggressiveness (Narayanan et al., 2020). Hypoxia would also influence intercellular communication by varying the release and the uptake of EVs by the cells. Studies have shown that hypoxia-derived tumor EVs play an important role in gliomagenesis (Kore et al., 2018). Exosomes are small EVs that transport cytosolic biomolecules, such as miRNAs and proteins, from virtually all cells in the body to neighboring and distal cells via the endocytic pathway. Recently, EVs have received a significant interest as transporters of biological mediators and have shown to be an important messenger in the intercellular communication between the tumor and the TME (Sullivan et al., 2017). Tumor cells exclude EV to engage non-tumor cells present in the TME and reprogram these cells from their normal activity to be more pro-tumorigenic (Whiteside, 2016). The transfer of molecules via EVs has emerged as a key messenger in intercellular communication in the TME. These EVs transport a diverse selection of molecules, including proteins, lipids, or nucleic acid cargoes. Tumor cells exclude EVs to the non-tumor cells, resulting in molecular, transcriptional, and translational modifications that cause these cells to fabricate factors required for tumor growth and at the same time alter the function of these cells (Santos and Almeida, 2020). TME stromal cells would, in turn, generate their own EVs containing and transferring molecules not only to the tumor but also to other cells in the TME, enhancing their pro-tumorigenic activity (Kalluri, 2016). Thus, EVs are able to propagate and maintain the TME as well as regulate the redox environment. An imbalance in the redox status would also alter the quantity of exosomal cargo proteins and consequently influences the redox levels in the EV-receiving cells. For example, the redox-sensitive signaling pathway PI3K/Akt/endothelial NOS controls the exosomal release of angpoietin-2 that has a key function in the remodeling of tumor vascularity.

Besides facilitating the transformation of stromal cells, the oxidative TME plays a key role in the output of paracrine signals and matrix remodeling enzymes that directly affect tumor cells, resulting in proliferation and invasion. In this context, the role of redox regulation by the PTPases has emerged as a key signal-regulating mechanism (Frijhoff et al., 2014). Acidosis, usually associated with high concentrations of lactate, presents a crucial stress factor in TME and would affect the comportment of the tumor. Tumorigenesis leads to alterations in metabolism, resulting in an amplification in glycolysis, caused by aerobic glycolysis or the "Warburg effect," which triggers a prompt supply of energy that is correlated to an increased conversion of glucose to lactate (Gatenby and Gillies, 2004; Vander Heiden et al., 2009; Vaupel and Multhoff, 2017). Lactate has been shown to be associated with tumor progression, therapy resistance, and immune escape (Brizel et al., 2001; Sattler et al., 2010; Kahlon et al., 2016). Radiotherapy resistance could also be intensified by the antioxidant properties of lactate, which would neutralize the ROS produced by IR to cells. Moreover, studies have shown that acidosis supports cell motility and migration as well as the degradation and remodeling of the ECM (Goetze et al., 2011). Lactate has been implicated in tumor angiogenesis and the expression of GSC markers (Hjelmeland et al., 2011). Exposure to acidic conditions could result in autophagy, which, as stated earlier, is connected with the preservation of the GSC phenotype and resistance to therapy (Lomonaco et al., 2009; Peppicelli et al., 2017). Acidosis could also neutralize ROS associated with radiotherapy, inhibit radiationinduced apoptosis, enhance the activity of P-glycoprotein (P-gp), and/or reduce the rate of proliferation of tumor cells (Peppicelli et al., 2017). In addition, acidosis would reduce the immune 
response by affecting the infiltration of tumor cells and the cytokine release by $\mathrm{T}$ cells, impeding monocytes, blocking the cytotoxic activity of natural killer $(\mathrm{NK})$ and $\mathrm{CD}^{+} \mathrm{T}$ cells, and boosting the activity of MDSC (Vaupel and Multhoff, 2017).

Thus, high levels of ROS present in tumor cells could result from either an amplified metabolic activity, mitochondrial dysfunction, peroxisome activity, deregulated cell receptor signaling, oncogene activity, enhanced activity of cyclooxygenase, lysyl oxidase, and thymidine phosphorylase, or communication with the immune infiltrate (Babior, 1999; Storz, 2005), suggesting that ROS and RNS can support numerous facets of tumor development and progression.

\section{PIVOTAL FUNCTION OF ANTIOXIDANT IN GLIOBLASTOMA: EFFECT OF NUTRITION}

It is now accepted that the synergistic effects of active compounds present in fruit and vegetables are responsible for their anticancer actions, and studies have shown a reverse effect of a diet rich in antioxidants in GBM (Chen et al., 2002; TedeschiBlok et al., 2006). Numerous studies have suggested that modulation of metabolism and ROS production by specific natural dietary constituents, such as phytoestrogens, flavonoids, polyunsaturated fatty acids, and vitamins, may have a protective action against cancers.

We used an ethylnitrosourea (ENU)-induced malignant GBM pregnant rat model developed from Koestner et al. (1971) to explore the influence of nutrition on gliomagenesis using an experimental diet (PtcD) composed of different constituents suggested to interfere in carcinogenesis, mainly phytochemicals, and its effects were compared to a diet without the phytochemicals (StD). In male rats fed the PtcD, the frequency of GBM was clearly diminished compared to that of rats fed the StD; however, in females, the outcome was negligible. An evaluation of the gene expression of proteins implicated in proliferation, apoptosis, and response to OS in male brain tumors depicted that the inhibition of the systemic effects (loss of body weight and liver mass, plus reduced liver mitochondria mass) was linked to an increase in Bcl-2 and catalase and a decrease in Ki-67, SOD-1, and SOD-2 (Pouliquen et al., 2008). These data suggested that the degree of aggressiveness of GBM could be controlled by dietary interventions and recommended that some phytochemicals with antioxidant properties could participate to the mechanism. We explored this hypothesis in a study using SUVIMAX-like diet ("Supplementation en Vitamines et Minéraux Antioxydants"), where rats were fed with a diet enriched with alpha-tocopherol, beta-carotene, vitamin C, zinc, and sodium selenite. We observed that this diet was associated with a considerable lag in the clinical signs of the disease but not a statistically significant difference in the incidence of glioma in an ENU model. The SUVIMAX-like diet decreased the candidate markers of tumor aggressiveness and gliomagenesis progression. The expression of the mRNA of two common markers in human glioma, SOD-2 and IGFBP5 (insulin growth factor binding protein), was reduced in the tumors of rats fed the antioxidant diet. In addition, the transcripts of two markers linked to brain tumor proliferation, PDGFR- $\beta$ (platelet-derived growth factor receptor beta), and Ki-67 were also significantly decreased. Overall, our results suggested a protective role for antioxidants in restraining the aggressiveness and, to some extent, evolution of GBM in a rat model (Hervouet et al., 2013).

Studies have highlighted the protective roles of hormones (Kabat et al., 2010; Zhou et al., 2019), and vitamins (Pouliquen et al., 2008; Kyritsis et al., 2011) in GBM as well as in other cancers (Han et al., 2015). However, the implication of ROS in the observed protection remains to be investigated.

\section{CONCLUSION AND FUTURE DIRECTIONS}

The oncogenic activity of oxidants hinges on four principal functions in tumorigenesis. Firstly, the mutagenic potential of oxidants could be implicated in the initiation of tumorigenesis. A considerable amount of mutagenic DNA damage in cells can be attributed to endogenous ROS and RNS; two of the principal candidates being hydroxyl radical $\left(\mathrm{OH}^{-}\right)$and peroxinitrite $\left(\mathrm{ONOO}^{-}\right)$, both of which have 8-oxo-guanine and single- and/or double-strand DNA breaks (Marnett, 2000). Secondly, the influence of oxidants on intracellular signaling pathways regulating cell proliferation and survival would promote tumorigenesis (Cerutti, 1985). Indeed low doses of hydrogen peroxide $\left(\mathrm{H}_{2} \mathrm{O}_{2}\right)$ and superoxide $\left(\mathrm{O}_{2}^{-}\right)$have been shown to stimulate cell proliferation in several tumors (Storz, 2005). ROS may diminish the requirement of cells for growth factors by decreasing the activation level of cognate receptor tyrosine kinase (RTK) or by trans-activating receptors in a ligandindependent manner (Rhee et al., 2000). Since RTK is linked to many downstream signaling cascades, numerous growth-related signaling actions triggered by oxidants could partially mimic the upstream activation of RTK-dependent signaling (Pani et al., 2000). Thirdly, the oxidants have impact on cell motility and invasiveness. Data suggest that tumor evolution is closely linked to the hypoxic TME in tumor lesions (Allen and Jones, 2011). The production of ROS in mild hypoxic environments could be the result of deregulation of mitochondrial respiration (Klimova and Chandel, 2008). Finally, the role of oxidants in stromal reactions is necessary for tumor progression and dissemination, such as inflammation/repair and angiogenesis (Comito et al., 2011). Indeed hypoxia that arises at the start of tumor growth and produces cell necrosis results in the activation of hypoxiaresponsive genes in tumor and non-tumor cells. It also supports the deployment and persistence of immune cells that are mainly glycolytic, including macrophages that generate large amounts of ROS. This has huge concerns for the cells present in this niche, as they must adjust to survive in this very oxidative environment. The increased levels of ROS also stimulate pathways in leukocytes to secrete more cytokines that support tumor growth, resulting in new cellular mutations, and could transform other cells and induce apoptosis. 
In the future, it would be interesting to study the impact of oxidative stress in new therapies such as immune or oncolytic virus-based therapies. Similarly, ROS production effects on radiation therapies have been described, but their radiosensitizing modulation properties at the chemical and biological levels need to be completed. Finally, since ROS production can be partially controlled positively or negatively by nutrition and/or by pollutants, it remains to be established how environmental factors could be incorporated into treatment strategies.

\section{REFERENCES}

Agostinelli, E., and Seiler, N. (2006). Non-irradiation-derived reactive oxygen species (ROS) and cancer: therapeutic implications. Amino Acids 31, 341-355. doi: 10.1007/s00726-005-0271-8

Allen, M., and Jones, J. (2011). Jekyll and Hyde: the role of the microenvironment on the progression of cancer. J. Pathol. 223, 162-176. doi: 10.1002/path.2803

Annabi, B., Laflamme, C., Sina, A., Lachambre, M.-P., and Béliveau, R. (2009). A MT1-MMP/NF-kappaB signaling axis as a checkpoint controller of COX2 expression in CD133+ U87 glioblastoma cells. J. Neuroinflamm. 6:8. doi: 10.1186/1742-2094-6-8

Anrather, J., Racchumi, G., and Iadecola, C. (2006). NF-kappaB regulates phagocytic NADPH oxidase by inducing the expression of gp91phox. J. Biol. Chem 281, 5657-5667. doi: 10.1074/jbc.M506172200

Babior, B. M. (1999). NADPH oxidase: an update. Blood 93, 1464-1476. doi: 10.1182/blood.V93.5.1464

Badie, B., and Schartner, J. M. (2000). Flow cytometric characterization of tumorassociated macrophages in experimental gliomas. Neurosurgery 46, 957-961; discussion 961-962. doi: 10.1227/00006123-200004000-00035

Baker, J. R., Vuppusetty, C., Colley, T., Papaioannou, A. I., Fenwick, P., Donnelly, L., et al. (2016). Oxidative stress dependent microRNA-34a activation via PI3K $\alpha$ reduces the expression of sirtuin- 1 and sirtuin- 6 in epithelial cells. Sci. Rep. 6:35871. doi: 10.1038/srep35871

Bao, S., Wu, Q., McLendon, R. E., Hao, Y., Shi, Q., Hjelmeland, A. B., et al. (2006). Glioma stem cells promote radioresistance by preferential activation of the DNA damage response. Nature 444, 756-760. doi: 10.1038/nature05236

Baulch, J. E., Geidzinski, E., Tran, K. K., Yu, L., Zhou, Y.-H., and Limoli, C. L. (2016). Irradiation of primary human gliomas triggers dynamic and aggressive survival responses involving microvesicle signaling. Environ. Mol. Mutagen. 57, 405-415. doi: 10.1002/em.21988

Beier, C. P., Kumar, P., Meyer, K., Leukel, P., Bruttel, V., Aschenbrenner, I., et al. (2012). The cancer stem cell subtype determines immune infiltration of glioblastoma. Stem Cells Dev. 21, 2753-2761. doi: 10.1089/scd.2011.0660

Bhat, K. P. L., Balasubramaniyan, V., Vaillant, B., Ezhilarasan, R., Hummelink, K., Hollingsworth, F., et al. (2013). Mesenchymal differentiation mediated by NF- $\kappa \mathrm{B}$ promotes radiation resistance in glioblastoma. Cancer Cell 24, 331-346. doi: 10.1016/j.ccr.2013.08.001

Bissell, M. J., and Radisky, D. (2001). Putting tumours in context. Nat. Rev. Cancer 1, 46-54. doi: 10.1038/35094059

Brantley, E. C., and Benveniste, E. N. (2008). Signal transducer and activator of transcription-3: a molecular hub for signaling pathways in gliomas. Mol. Cancer Res. 6, 675-684. doi: 10.1158/1541-7786.MCR-07-2180

Brierley, D. J., and Martin, S. A. (2013). Oxidative stress and the DNA mismatch repair pathway. Antioxid. Redox Signal 18, 2420-2428. doi: 10.1089/ars.2012.4994

Brizel, D. M., Schroeder, T., Scher, R. L., Walenta, S., Clough, R. W., Dewhirst, M. W., et al. (2001). Elevated tumor lactate concentrations predict for an increased risk of metastases in head-and-neck cancer. Int. J. Radiat. Oncol. Biol. Phys. 51, 349-353. doi: 10.1016/S0360-3016(01)01630-3

Brooks, L. J., and Parrinello, S. (2017). Vascular regulation of glioma stem-like cells: a balancing act. Curr. Opin. Neurobiol. 47, 8-15. doi: 10.1016/j.conb.2017.06.008

Buccarelli, M., Marconi, M., Pacioni, S., De Pascalis, I., D’Alessandris, Q. G., Martini, M., et al. (2018). Inhibition of autophagy increases susceptibility of

\section{AUTHOR CONTRIBUTIONS}

$\mathrm{CO}, \mathrm{LO}, \mathrm{LL}$, and FV wrote the first draft and the following versions. All authors contributed to the article and approved the submitted version.

\section{FUNDING}

This work was supported by INSERM/University of Nantes.

glioblastoma stem cells to temozolomide by igniting ferroptosis. Cell Death Dis. 9, 1-17. doi: 10.1038/s41419-018-0864-7

Burdon, R. H., Gill, V., and Rice-Evans, C. (1990). Oxidative stress and tumour cell proliferation. Free Radic. Res. Commun. 11, 65-76. doi: 10.3109/10715769009109669

Cerutti, P. A. (1985). Prooxidant states and tumor promotion. Science 227, 375381. doi: $10.1126 /$ science. 2981433

Chang, K.-Y., Hsu, T.-I., Hsu, C.-C., Tsai, S.-Y., Liu, J.-J., Chou, S.-W., et al. (2017a). Specificity protein 1-modulated superoxide dismutase 2 enhances temozolomide resistance in glioblastoma, which is independent of O6-methylguanine-DNA methyltransferase. Redox Biol. 13, 655-664. doi: 10.1016/j.redox.2017.08.005

Chang, K.-Y., Huang, C.-T., Hsu, T.-I., Hsu, C.-C., Liu, J.-J., Chuang, C.-K., et al. (2017b). Stress stimuli induce cancer-stemness gene expression via Sp1 activation leading to therapeutic resistance in glioblastoma. Biochem. Biophys. Res. Commun. 493, 14-19. doi: 10.1016/j.bbrc.2017.09.095

Chen, H., Ward, M. H., Tucker, K. L., Graubard, B. I., McComb, R. D., Potischman, N. A., et al. (2002). Diet and risk of adult glioma in eastern Nebraska, United States. Cancer Causes Control 13, 647-655. doi: 10.1023/A:1019527225197

Chen, J., Li, Y., Yu, T.-S., McKay, R. M., Burns, D. K., Kernie, S. G., et al. (2012). A restricted cell population propagates glioblastoma growth after chemotherapy. Nature 488, 522-526. doi: 10.1038/nature11287

Chien, C.-H., Chuang, J.-Y., Yang, S.-T., Yang, W.-B., Chen, P.-Y., Hsu, T.-I., et al. (2019). Enrichment of superoxide dismutase 2 in glioblastoma confers to acquisition of temozolomide resistance that is associated with tumor-initiating cell subsets. J. Biomed. Sci. 26:77. doi: 10.1186/s12929-019-0565-2

Comito, G., Calvani, M., Giannoni, E., Bianchini, F., Calorini, L., Torre, E., et al. (2011). HIF-1 $\alpha$ stabilization by mitochondrial ROS promotes Met-dependent invasive growth and vasculogenic mimicry in melanoma cells. Free Radic. Biol. Med. 51, 893-904. doi: 10.1016/j.freeradbiomed.2011.05.042

Conti, A., Guli, C., La Torre, D., Tomasello, C., Angileri, F. F., and Aguennouz, M. (2010). Role of inflammation and oxidative stress mediators in gliomas. Cancers 2, 693-712. doi: $10.3390 /$ cancers2020693

Conti, A., Miscusi, M., Cardali, S., Germanò, A., Suzuki, H., Cuzzocrea, S., et al. (2007). Nitric oxide in the injured spinal cord: synthases crosstalk, oxidative stress and inflammation. Brain Res. Rev. 54, 205-218. doi: 10.1016/j.brainresrev.2007.01.013

Coppé, J.-P., Desprez, P.-Y., Krtolica, A., and Campisi, J. (2010). The senescenceassociated secretory phenotype: the dark side of tumor suppression. Annu. Rev. Pathol. 5, 99-118. doi: 10.1146/annurev-pathol-121808-102144

Costa, A., Scholer-Dahirel, A., and Mechta-Grigoriou, F. (2014). The role of reactive oxygen species and metabolism on cancer cells and their microenvironment. Semin. Cancer Biol. 25, 23-32. doi: 10.1016/j.semcancer.2013.12.007

Da Ros, M., De Gregorio, V., Iorio, A. L., Giunti, L., Guidi, M., de Martino, M., et al. (2018). Glioblastoma chemoresistance: the double play by microenvironment and blood-brain barrier. Int. J. Mol. Sci. 19:2879. doi: 10.3390/ijms1910 2879

Dalavaikodihalli Nanjaiah, N., Ramaswamy, P., Goswami, K., Fathima, K., H., and Borkotokey, M. (2019). Survival of glioblastoma cells in response to endogenous and exogenous oxidative challenges: possible implication of NMDA receptor-mediated regulation of redox homeostasis. Cell Biol. Int. 43, 1443-1452. doi: 10.1002/cbin.11193 
Deshors, P., Toulas, C., Arnauduc, F., Malric, L., Siegfried, A., Nicaise, Y., et al. (2019). Ionizing radiation induces endothelial transdifferentiation of glioblastoma stem-like cells through the Tie2 signaling pathway. Cell Death Dis. 10:816. doi: 10.1038/s41419-019-2055-6

Dewhirst, M. W., Cao, Y., and Moeller, B. (2008). Cycling hypoxia and free radicals regulate angiogenesis and radiotherapy response. Nat. Rev. Cancer 8, 425-437. doi: $10.1038 / \mathrm{nrc} 2397$

Dhar, S. K., and St Clair, D. K. (2012). Manganese superoxide dismutase regulation and cancer. Free Radic. Biol. Med. 52, 2209-2222. doi: 10.1016/j.freeradbiomed.2012.03.009

Diehn, M., Cho, R. W., Lobo, N. A., Kalisky, T., Dorie, M. J., Kulp, A. N., et al. (2009). Association of reactive oxygen species levels and radioresistance in cancer stem cells. Nature 458, 780-783. doi: 10.1038/nature07733

Dittmann, L. M., Danner, A., Gronych, J., Wolter, M., Stühler, K., Grzendowski, M., et al. (2012). Downregulation of PRDX1 by promoter hypermethylation is frequent in $1 \mathrm{p} / 19 \mathrm{q}$-deleted oligodendroglial tumours and increases radioand chemosensitivity of Hs683 glioma cells in vitro. Oncogene 31, 3409-3418. doi: 10.1038/onc.2011.513

Djavaheri-Mergny, M., Javelaud, D., Wietzerbin, J., and Besançon, F. (2004). NF- $\kappa \mathrm{B}$ activation prevents apoptotic oxidative stress via an increase of both thioredoxin and MnSOD levels in TNF $\alpha$-treated Ewing sarcoma cells. FEBS Lett. 578, 111-115. doi: 10.1016/j.febslet.2004.10.082

Fan, Q.-W., Cheng, C., Hackett, C., Feldman, M., Houseman, B. T., Nicolaides, T., et al. (2010). Akt and autophagy cooperate to promote survival of drug-resistant glioma. Sci. Signal. 3:ra81. doi: 10.1126/scisignal.2001017

Fan, Z., Wirth, A.-K., Chen, D., Wruck, C. J., Rauh, M., Buchfelder, M., et al. (2017). Nrf2-Keap1 pathway promotes cell proliferation and diminishes ferroptosis. Oncogenesis 6:e371. doi: 10.1038/oncsis.2017.65

Fang, J. S., Gillies, R. D., and Gatenby, R. A. (2008). Adaptation to hypoxia and acidosis in carcinogenesis and tumor progression. Semin. Cancer Biol. 18, 330-337. doi: 10.1016/j.semcancer.2008.03.011

Feng, F., Zhang, M., Yang, C., Heng, X., and Wu, X. (2019). The dual roles of autophagy in gliomagenesis and clinical therapy strategies based on autophagic regulation mechanisms. Biomed. Pharmacother. 120:109441. doi: 10.1016/j.biopha.2019.109441

Fiaschi, T., and Chiarugi, P. (2012). Oxidative stress, tumor microenvironment, and metabolic reprogramming: a diabolic liaison. Int. J. Cell Biol. 2012:762825. doi: 10.1155/2012/762825

Ford, K., Hanley, C. J., Mellone, M., Szyndralewiez, C., Heitz, F., Wiesel, P., et al. (2020). NOX4 inhibition potentiates immunotherapy by overcoming cancerassociated fibroblast-mediated CD8 T-cell exclusion from tumors. Cancer Res. 80, 1846-1860. doi: 10.1158/0008-5472.CAN-19-3158

Frijhoff, J., Dagnell, M., Godfrey, R., and Ostman, A. (2014). Regulation of protein tyrosine phosphatase oxidation in cell adhesion and migration. Antioxid. Redox Signal. 20, 1994-2010. doi: 10.1089/ars.2013.5643

Frisch, J., Angenendt, A., Hoth, M., Prates Roma, L., and Lis, A. (2019). STIM-orai channels and reactive oxygen species in the tumor microenvironment. Cancers 11:457. doi: 10.3390/cancers11040457

Gatenby, R. A., and Gillies, R. J. (2004). Why do cancers have high aerobic glycolysis? Nat. Rev. Cancer 4, 891-899. doi: 10.1038/nrc1478

Giannoni, E., Parri, M., and Chiarugi, P. (2012). EMT and oxidative stress: a bidirectional interplay affecting tumor malignancy. Antioxid. Redox Signal. 16, 1248-1263. doi: 10.1089/ars.2011.4280

Goetze, K., Walenta, S., Ksiazkiewicz, M., Kunz-Schughart, L. A., and MuellerKlieser, W. (2011). Lactate enhances motility of tumor cells and inhibits monocyte migration and cytokine release. Int. J. Oncol. 39, 453-463. doi: 10.3892/ijo.2011.1055

Greaves, M., and Maley, C. C. (2012). Clonal evolution in cancer. Nature 481, 306-313. doi: 10.1038/nature10762

Grivennikov, S. I., Greten, F. R., and Karin, M. (2010). Immunity, inflammation, and cancer. Cell 140, 883-899. doi: 10.1016/j.cell.2010.01.025

Groussard, C., Morel, I., Chevanne, M., Monnier, M., Cillard, J., and Delamarche, A. (2000). Free radical scavenging and antioxidant effects of lactate ion: an in vitro study. J. Appl. Physiol. 89, 169-175. doi: 10.1152/jappl.2000.89.1.169

Haas, B., Schütte, L., Wos-Maganga, M., Weickhardt, S., Timmer, M., and Eckstein, N. (2018). Thioredoxin confers intrinsic resistance to cytostatic drugs in human glioma cells. Int. J. Mol. Sci. 19:2874. doi: 10.3390/ijms19102874
Han, S., Lv, X., Wang, Y., Gong, H., Zhang, C., Tong, A., et al. (2015). Effect and mechanism of peroxisome proliferator-activated receptor$\gamma$ on the drug resistance of the U-87 MG/CDDP human malignant glioma cell line. Mol. Med. Rep. 12, 2239-2246. doi: 10.3892/mmr.201 5.3625

Heddleston, J. M., Li, Z., McLendon, R. E., Hjelmeland, A. B., and Rich, J. N. (2009). The hypoxic microenvironment maintains glioblastoma stem cells and promotes reprogramming towards a cancer stem cell phenotype. Cell Cycle 8, 3274-3284. doi: 10.4161/cc.8.20.9701

Hegi, M., Diserens, A., and Hamou, M. (2004). Temozolomide (TMZ) targets only glioblastoma with a silenced MGMT-gene. Results of a translational companion study to EORTC 26981/NCIC CE.3 of radiotherapy \pm TMZ. Eur. J. Cancer 2:3-228. doi: 10.1016/S1359-6349(04)80039-9

Hervouet, E., Staehlin, O., Pouliquen, D., Debien, E., Cartron, P.-F., Menanteau, J., et al. (2013). Antioxidants delay clinical signs and systemic effects of ENU induced brain tumors in rats. Nutr. Cancer 65, 686-694. doi: 10.1080/01635581.2013.789541

Hira, V. V. V., Ploegmakers, K. J., Grevers, F., Verbovšek, U., SilvestreRoig, C., Aronica, E., et al. (2015). CD133+ and Nestin+ Glioma StemLike Cells Reside Around CD31+ Arterioles in Niches that Express SDF-1 $\alpha$, CXCR4, Osteopontin and Cathepsin K. J. Histochem. Cytochem. 63, 481-493. doi: 10.1369/0022155415581689

Hira, V. V. V., Verbovšek, U., Breznik, B., Srdič, M., Novinec, M., Kakar, H., et al. (2017). Cathepsin K cleavage of SDF-1 $\alpha$ inhibits its chemotactic activity towards glioblastoma stem-like cells. Biochim. Biophys. Acta. Mol. Cell. Res. 1864, 594-603. doi: 10.1016/j.bbamcr.2016.12.021

Hirschhaeuser, F., Sattler, U. G. A., and Mueller-Klieser, W. (2011). Lactate: a metabolic key player in cancer. Cancer Res. 71, 6921-6925. doi: 10.1158/0008-5472.CAN-11-1457

Hjelmeland, A. B., Wu, Q., Heddleston, J. M., Choudhary, G. S., MacSwords, J., Lathia, J. D., et al. (2011). Acidic stress promotes a glioma stem cell phenotype. Cell Death Differ. 18, 829-840. doi: 10.1038/cdd.2010.150

Hsieh, C.-H., Lin, Y.-J., Wu, C.-P., Lee, H.-T., Shyu, W.-C., and Wang, C.-C. (2015). Livin contributes to tumor hypoxia-induced resistance to cytotoxic therapies in glioblastoma multiforme. Clin. Cancer Res. 21, 460-470. doi: 10.1158/1078-0432.CCR-14-0618

Hsieh, C.-H., Wu, C.-P., Lee, H.-T., Liang, J.-A., Yu, C.-Y., and Lin, Y.-J. (2012). NADPH oxidase subunit 4 mediates cycling hypoxia-promoted radiation resistance in glioblastoma multiforme. Free Radic. Biol. Med. 53, 649-658. doi: 10.1016/j.freeradbiomed.2012.06.009

Ito, K., and Suda, T. (2014). Metabolic requirements for the maintenance of selfrenewing stem cells. Nat. Rev. Mol. Cell Biol. 15, 243-256. doi: 10.1038/nrm3772

Janiszewska, M., Suvá, M. L., Riggi, N., Houtkooper, R. H., Auwerx, J., ClémentSchatlo, V., et al. (2012). Imp2 controls oxidative phosphorylation and is crucial for preserving glioblastoma cancer stem cells. Genes Dev. 26, 1926-1944. doi: $10.1101 / \mathrm{gad} .188292 .112$

Jaramillo, M. C., and Zhang, D. D. (2013). The emerging role of the Nrf2-Keap1 signaling pathway in cancer. Genes Dev. 27, 2179-2191. doi: $10.1101 /$ gad.225680.113

Jiang, G., Li, L.-T., Xin, Y., Zhang, L., Liu, Y.-Q., and Zheng, J.-N. (2012) Strategies to improve the killing of tumors using temozolomide: targeting the DNA repair protein MGMT. Curr. Med. Chem. 19, 3886-3892. doi: 10.2174/092986712802002446

Jin, X., Kim, L. J. Y., Wu, Q., Wallace, L. C., Prager, B. C., Sanvoranart, T., et al. (2017). Targeting glioma stem cells through combined BMI1 and EZH2 inhibition. Nat. Med. 23, 1352-1361. doi: 10.1038/n m.4415

Jin, Z., Zhan, T., Tao, J., Xu, B., Zheng, H., Cheng, Y., et al. (2017). MicroRNA34a induces transdifferentiation of glioma stem cells into vascular endothelial cells by targeting Notch pathway. Biosci. Biotechnol. Biochem. 81, 1899-1907. doi: 10.1080/09168451.2017.1364965

Johnson, D. E. (2015). The ubiquitin-proteasome system: opportunities for therapeutic intervention in solid tumors. Endocr. Relat. Cancer 22, T1-17. doi: 10.1530/ERC-14-0005

Kabat, G. C., Etgen, A. M., and Rohan, T. E. (2010). Do steroid hormones play a role in the etiology of glioma? Cancer Epidemiol. Biomarkers Prev. 19, 2421-2427. doi: 10.1158/1055-9965.EPI-10-0658 
Kahlon, A. S., Alexander, M., Kahlon, A., and Wright, J. (2016). Lactate levels with glioblastoma multiforme. Proceedings 29, 313-314. doi: 10.1080/08998280.2016.11929449

Kairisalo, M., Korhonen, L., Blomgren, K., and Lindholm, D. (2007). Xlinked inhibitor of apoptosis protein increases mitochondrial antioxidants through NF-кB activation. Biochem. Biophys. Res. Commun. 364, 138-144. doi: $10.1016 /$ j.bbrc.2007.09.115

Kalluri, R. (2016). The biology and function of exosomes in cancer. J. Clin. Invest. 126, 1208-1215. doi: 10.1172/JCI81135

Kanzawa, T., Germano, I. M., Komata, T., Ito, H., Kondo, Y., and Kondo, S. (2004). Role of autophagy in temozolomide-induced cytotoxicity for malignant glioma cells. Cell Death Differ. 11, 448-457. doi: 10.1038/sj.cdd.4401359

Ke, C., Tran, K., Chen, Y., Di Donato, A. T., Yu, L., Hu, Y., et al. (2014). Linking differential radiation responses to glioma heterogeneity. Oncotarget 5, 1657-1665. doi: 10.18632/oncotarget.1823

Kensler, T. W., Wakabayashi, N., and Biswal, S. (2007). Cell survival responses to environmental stresses via the Keap1Nrf2-ARE pathway. Annu. Rev. Pharmacol. Toxicol. 47, 89-116. doi: 10.1146/annurev.pharmtox.46.120604.141046

Kim, S.-H., Kim, K.-Y., Park, S.-G., Yu, S.-N., Kim, Y.-W., Nam, H.-W., et al. (2017). Mitochondrial ROS activates ERK/autophagy pathway as a protected mechanism against deoxypodophyllotoxin-induced apoptosis. Oncotarget 8, 111581-111596. doi: 10.18632/oncotarget.22875

Kim, S.-H., Kwon, C.-H., and Nakano, I. (2014). Detoxification of oxidative stress in glioma stem cells: mechanism, clinical relevance, and therapeutic development. J. Neurosci. Res. 92, 1419-1424. doi: 10.1002/jnr.23431

Kim, S. S., Seong, S., Lim, S. H., and Kim, S. Y. (2013). Biliverdin reductase plays a crucial role in hypoxia-induced chemoresistance in human glioblastoma. Biochem. Biophys. Res. Commun. 440, 658-663. doi: 10.1016/j.bbrc.2013.09.120

Klimova, T., and Chandel, N. S. (2008). Mitochondrial complex III regulates hypoxic activation of HIF. Cell Death Differ. 15, 660-666. doi: $10.1038 /$ sj.cdd. 4402307

Koestner, A., Swenberg, J. A., and Wechsler, W. (1971). Transplacental production with ethylnitrosourea of neoplasms of the nervous system in Sprague-Dawley rats. Am. J. Pathol. 63, 37-56.

Kong, Q., Beel, J. A., and Lillehei, K. O. (2000). A threshold concept for cancer therapy. Med Hypotheses 55, 29-35. doi: 10.1054/mehy.1999.0982

Kore, R. A., Edmondson, J. L., Jenkins, S. V., Jamshidi-Parsian, A., Dings, R. P. M., Reyna, N. S., et al. (2018). Hypoxia-derived exosomes induce putative altered pathways in biosynthesis and ion regulatory channels in glioblastoma cells. Biochem. Biophys. Rep. 14, 104-113. doi: 10.1016/j.bbrep.2018.03.008

Krause, M. S., Oliveira, L. P., Silveira, E. M. S., Vianna, D. R., Rossato, J. S., Almeida, B. S., et al. (2007). MRP1/GS-X pump ATPase expression: is this the explanation for the cytoprotection of the heart against oxidative stress-induced redox imbalance in comparison to skeletal muscle cells? Cell Biochem. Funct. 25, 23-32. doi: 10.1002/cbf.1343

Kubli, D. A., and Gustafsson, A. B. (2012). Mitochondria and mitophagy: the yin and yang of cell death control. Circ. Res. 111, 1208-1221. doi: 10.1161/CIRCRESAHA.112.265819

Kyritsis, A. P., Bondy, M. L., and Levin, V. A. (2011). Modulation of glioma risk and progression by dietary nutrients and antiinflammatory agents. Nutr. Cancer 63, 174-184. doi: 10.1080/01635581.2011.523807

Lagadec, C., Vlashi, E., Della Donna, L., Dekmezian, C., and Pajonk, F. (2012). Radiation-induced reprogramming of breast cancer cells. Stem Cells 30, 833-844. doi: 10.1002/stem.1058

Lan, M. L., Acharya, M. M., Tran, K. K., Bahari-Kashani, J., Patel, N. H., Strnadel, J., et al. (2012). Characterizing the radioresponse of pluripotent and multipotent human stem cells. PLoS One 7:e50048. doi: 10.1371/journal.pone.0050048

Lan, X., Jörg, D. J., Cavalli, F. M. G., Richards, L. M., Nguyen, L. V., Vanner, R. J., et al. (2017). Fate mapping of human glioblastoma reveals an invariant stem cell hierarchy. Nature 549, 227-232. doi: 10.1038/nature23666

Lee, H.-C., Kim, D.-W., Jung, K.-Y., Park, I.-C., Park, M.-J., Kim, M.-S., et al. (2004). Increased expression of antioxidant enzymes in radioresistant variant from U251 human glioblastoma cell line. Int. J. Mol. Med. 13, 883-887. doi: 10.3892/ijmm.13.6.883

Lee, J. H., Lee, J. E., Kahng, J. Y., Kim, S. H., Park, J. S., Yoon, S. J., et al. (2018). Human glioblastoma arises from subventricular zone cells with low-level driver mutations. Nature 560, 243-247. doi: 10.1038/s41586-018-0389-3
Li, X., Wu, W. K. K., Sun, B., Cui, M., Liu, S., Gao, J., et al. (2011). Dihydroptychantol A, a macrocyclic bisbibenzyl derivative, induces autophagy and following apoptosis associated with p53 pathway in human osteosarcoma U2OS cells. Toxicol. Appl. Pharmacol. 251, 146-154. doi: 10.1016/j.taap.2010.12.007

Li, Z., Bao, S., Wu, Q., Wang, H., Eyler, C., Sathornsumetee, S., et al. (2009). Hypoxia-inducible factors regulate tumorigenic capacity of glioma stem cells. Cancer Cell 15, 501-513. doi: 10.1016/j.ccr.2009.03.018

Lin, C.-C., Chiang, L.-L., Lin, C.-H., Shih, C.-H., Liao, Y.-T., Hsu, M.-J., et al. (2007). Transforming growth factor-betal stimulates heme oxygenase1 expression via the PI3K/Akt and NF-кB pathways in human lung epithelial cells. Eur. J. Pharmacol. 560, 101-109. doi: 10.1016/j.ejphar.2007.01.025

Lin, C.-J., Lee, C.-C., Shih, Y.-L., Lin, T.-Y., Wang, S.-H., Lin, Y.-F., et al. (2012). Resveratrol enhances the therapeutic effect of temozolomide against malignant glioma in vitro and in vivo by inhibiting autophagy. Free Radic. Biol. Med. 52, 377-391. doi: 10.1016/j.freeradbiomed.2011.10.487

Liu, H., Lv, L., and Yang, K. (2015). Chemotherapy targeting cancer stem cells. Am. J. Cancer Res. 5, 880-893. Available online at: https://www.ncbi.nlm.nih.gov/ pmc/articles/PMC4449424/

Liu, Y., Li, Q., Zhou, L., Xie, N., Nice, E. C., Zhang, H., et al. (2016). Cancer drug resistance: redox resetting renders a way. Oncotarget 7, 42740-42761. doi: 10.18632/oncotarget.8600

Lo Dico, A., Martelli, C., Diceglie, C., Lucignani, G., and Ottobrini, L. (2018). Hypoxia-inducible factor- $1 \alpha$ activity as a switch for glioblastoma responsiveness to temozolomide. Front. Oncol. 8:249. doi: 10.3389/fonc. 2018.00249

Lo Dico, A., Salvatore, D., Martelli, C., Ronchi, D., Diceglie, C., Lucignani, G., et al. (2019). Intracellular redox-balance involvement in temozolomide resistance-related molecular mechanisms in glioblastoma. Cells 8:1315. doi: $10.3390 /$ cells 8111315

Lomonaco, S. L., Finniss, S., Xiang, C., Decarvalho, A., Umansky, F., Kalkanis, S. N., et al. (2009). The induction of autophagy by gamma-radiation contributes to the radioresistance of glioma stem cells. Int. J. Cancer 125, 717-722. doi: $10.1002 /$ ijc. 24402

Louis, D. N., Perry, A., Reifenberger, G., von Deimling, A., Figarella-Branger, D., Cavenee, W. K., et al. (2016). The 2016 World Health Organization Classification of Tumors of the Central Nervous System: a summary. Acta Neuropathol. 131, 803-820. doi: 10.1007/s00401-016-1545-1

Lu, X., Yan, C. H., Yuan, M., Wei, Y., Hu, G., and Kang, Y. (2010). In vivo dynamics and distinct functions of hypoxia in primary tumor growth and organotropic metastasis of breast cancer. Cancer Res. 70, 3905-3914. doi: 10.1158/0008-5472.CAN-09-3739

Lyakhovich, A., and Lleonart, M. E. (2016). Bypassing mechanisms of mitochondria-mediated cancer stem cells resistance to chemoand radiotherapy. Oxid. Med. Cell Longev. 2016:1716341. doi: $10.1155 / 2016 / 1716341$

Ma, Q. (2013). Role of nrf2 in oxidative stress and toxicity. Annu. Rev. Pharmacol. Toxicol. 53, 401-426. doi: 10.1146/annurev-pharmtox-011112-140320

MacLeod, G., Bozek, D. A., Rajakulendran, N., Monteiro, V., Ahmadi, M., Steinhart, Z., et al. (2019). Genome-Wide CRISPR-Cas9 Screens Expose Genetic Vulnerabilities and Mechanisms of Temozolomide Sensitivity in Glioblastoma Stem Cells. Cell. Rep. 27, 971-986.e9. doi: 10.1016/j.celrep.2019.03.047

Maier, P., Hartmann, L., Wenz, F., and Herskind, C. (2016). Cellular pathways in response to ionizing radiation and their targetability for tumor radiosensitization. Int. J. Mol. Sci. 17:102. doi: 10.3390/ijms17010102

Mao, P., Joshi, K., Li, J., Kim, S.-H., Li, P., Santana-Santos, L., et al. (2013). Mesenchymal glioma stem cells are maintained by activated glycolytic metabolism involving aldehyde dehydrogenase 1A3. Proc. Natl. Acad. Sci. U. S. A. 110, 8644-8649. doi: 10.1073/pnas.1221478110

Marks, P. A. (2006). Thioredoxin in cancer-role of histone deacetylase inhibitors Semin. Cancer Biol. 16, 436-443. doi: 10.1016/j.semcancer.2006.09.005

Marnett, L. J. (2000). Oxyradicals and DNA damage. Carcinogenesis 21, 361-370. doi: 10.1093/carcin/21.3.361

Matschke, J., Riffkin, H., Klein, D., Handrick, R., Lüdemann, L., Metzen, E., et al. (2016). Targeted inhibition of glutamine-dependent glutathione metabolism overcomes death resistance induced by chronic cycling hypoxia. Antioxid. Redox Signal. 25, 89-107. doi: 10.1089/ars.2015.6589 
Mittal, M., Siddiqui, M. R., Tran, K., Reddy, S. P., and Malik, A. B. (2014). Reactive oxygen species in inflammation and tissue injury. Antioxid. Redox Signal. 20, 1126-1167. doi: 10.1089/ars.2012.5149

Morgan, M. J., and Liu, Z. (2011). Crosstalk of reactive oxygen species and NF-кB signaling. Cell Res. 21, 103-115. doi: 10.1038/cr.2010.178

Murphy, M. P. (2009). How mitochondria produce reactive oxygen species. Biochem J. 417, 1-13. doi: 10.1042/BJ20081386

Nagai, S., Washiyama, K., Kurimoto, M., Takaku, A., Endo, S., and Kumanishi, T. (2002). Aberrant nuclear factor- $\kappa B$ activity and its participation in the growth of human malignant astrocytoma. J. Neurosurg. 96, 909-917. doi: 10.3171/jns.2002.96.5.0909

Nakai, E., Park, K., Yawata, T., Chihara, T., Kumazawa, A., Nakabayashi, H., et al. (2009). Enhanced MDR1 expression and chemoresistance of cancer stem cells derived from glioblastoma. Cancer Invest. 27, 901-908. doi: 10.3109/07357900801946679

Narayanan, D., Ma, S., and Özcelik, D. (2020). Targeting the redox landscape in cancer therapy. Cancers 12:1706. doi: 10.3390/cancers 12071706

Nathan, C., and Cunningham-Bussel, A. (2013). Beyond oxidative stress: an immunologist's guide to reactive oxygen species. Nat. Rev. Immunol. 13, 349-361. doi: 10.1038/nri3423

Nishiya, T., Uehara, T., Kaneko, M., and Nomura, Y. (2000). Involvement of nuclear factor- $\kappa \mathrm{B}(\mathrm{NF}-\kappa \mathrm{B})$ signaling in the expression of inducible nitric oxide synthase (iNOS) gene in rat C6 glioma cells. Biochem. Biophys. Res. Commun. 275, 268-273. doi: 10.1006/bbrc.2000.3293

Oliva, C. R., Moellering, D. R., Gillespie, G. Y., and Griguer, C. E. (2011). Acquisition of chemoresistance in gliomas is associated with increased mitochondrial coupling and decreased ROS production. PLoS One 6:e24665. doi: 10.1371/journal.pone.0024665

Orimo, A., Gupta, P. B., Sgroi, D. C., Arenzana-Seisdedos, F., Delaunay, T., Naeem, R., et al. (2005). Stromal fibroblasts present in invasive human breast carcinomas promote tumor growth and angiogenesis through elevated SDF1/CXCL12 secretion. Cell 121, 335-348. doi: 10.1016/j.cell.2005.02.034

Ortega, A. L., Mena, S., and Estrela, J. M. (2011). Glutathione in cancer cell death. Cancers (Basel) 3, 1285-1310. doi: 10.3390/cancers3011285

Ostrom, Q. T., Gittleman, H., Fulop, J., Liu, M., Blanda, R., Kromer, C., et al. (2015). CBTRUS statistical report: primary brain and central nervous system tumors diagnosed in the United States in 2008-2012. Neuro Oncol. 17(Suppl 4), iv1-iv62. doi: 10.1093/neuonc/nov189

Pan, H., Wang, H., Zhu, L., Wang, X., Cong, Z., Sun, K., et al. (2013). The involvement of Nrf2-ARE pathway in regulation of apoptosis in human glioblastoma cell U251. Neurol. Res. 35, 71-78. doi: 10.1179/1743132812Y.0000000094

Pani, G., Colavitti, R., Bedogni, B., Anzevino, R., Borrello, S., and Galeotti, T. (2000). A redox signaling mechanism for density-dependent inhibition of cell growth. J. Biol. Chem. 275, 38891-38899. doi: 10.1074/jbc.M007319200

Papandreou, I., Cairns, R. A., Fontana, L., Lim, A. L., and Denko, N. C. (2006). HIF1 mediates adaptation to hypoxia by actively downregulating mitochondrial oxygen consumption. Cell Metab. 3, 187-197. doi: 10.1016/j.cmet.2006.01.012

Park, H.-K., Hong, J.-H., Oh, Y. T., Kim, S. S., Yin, J., Lee, A.-J., et al. (2019). Interplay between TRAP1 and Sirtuin-3 modulates mitochondrial respiration and oxidative stress to maintain stemness of glioma stem cells. Cancer Res. 79, 1369-1382. doi: 10.1158/0008-5472.CAN-18-2558

Park, S. H., Chung, Y. M., Lee, Y. S., Kim, H. J., Kim, J. S., Chae, H. Z., et al. (2000). Antisense of human peroxiredoxin II enhances radiation-induced cell death. Clin. Cancer Res. 6, 4915-4920.

Peppicelli, S., Andreucci, E., Ruzzolini, J., Laurenzana, A., Margheri, F., Fibbi, G., et al. (2017). The acidic microenvironment as a possible niche of dormant tumor cells. Cell. Mol. Life Sci. 74, 2761-2771. doi: 10.1007/s00018-017-2496-y

Pham, C. G., Bubici, C., Zazzeroni, F., Papa, S., Jones, J., Alvarez, K., et al. (2004). Ferritin heavy chain upregulation by NF-кB inhibits TNF $\alpha-$ induced apoptosis by suppressing reactive oxygen species. Cell 119, 529-542. doi: 10.1016/j.cell.2004.10.017

Pistollato, F., Abbadi, S., Rampazzo, E., Persano, L., Della Puppa, A., Frasson, C., et al. (2010). Intratumoral hypoxic gradient drives stem cells distribution and MGMT expression in glioblastoma. Stem Cells 28, 851-862. doi: $10.1002 /$ stem.415

Polewski, M. D., Reveron-Thornton, R. F., Cherryholmes, G. A., Marinov, G. K., Cassady, K., and Aboody, K. S. (2016). Increased expression of system xc- in glioblastoma confers an altered metabolism and chemoresistance. Mol. Cancer Res 14, 1229-1242. doi: 10.1158/1541-7786.MCR-16-0028

Poschmann, G., Grzendowski, M., Stefanski, A., Bruns, E., Meyer, H. E., and Stühler, K. (2015). Redox proteomics reveal stress responsive proteins linking peroxiredoxin-1 status in glioma to chemosensitivity and oxidative stress. Biochim. Biophys. Acta 1854, 624-631. doi: 10.1016/j.bbapap.2014.11.011

Pouliquen, D., Olivier, C., Hervouet, E., Pedelaborde, F., Debien, E., Cabellec, M.T. L., et al. (2008). Dietary prevention of malignant glioma aggressiveness, implications in oxidant stress and apoptosis. Int. J. Cancer 123, 288-295. doi: $10.1002 /$ ijc. 23513

Rademakers, S. E., Span, P. N., Kaanders, J. H. A. M., Sweep, F. C. G. J., van der Kogel, A. J., and Bussink, J. (2008). Molecular aspects of tumour hypoxia. Mol. Oncol. 2, 41-53. doi: 10.1016/j.molonc.2008.03.006

Raghunand, N., and Gillies, R. J. (2000). pH and drug resistance in tumors. Drug Resist. Updat. 3, 39-47. doi: 10.1054/drup.2000.0119

Rajesh, Y., Biswas, A., Kumar, U., Das, S., Banerjee, I., Banik, P., et al. (2019). Targeting NFE2L2, a transcription factor upstream of MMP-2: a potential therapeutic strategy for temozolomide resistant glioblastoma. Biochem. Pharmacol. 164, 1-16. doi: 10.1016/j.bcp.2019.03.025

Rhee, S. G., Bae, Y. S., Lee, S. R., and Kwon, J. (2000). Hydrogen peroxide: a key messenger that modulates protein phosphorylation through cysteine oxidation. Sci. STKE 2000, pe1. doi: 10.1126/scisignal.532000pe1

Rocha, C. R. R., Kajitani, G. S., Quinet, A., Fortunato, R. S., and Menck, C. F. M. (2016). NRF2 and glutathione are key resistance mediators to temozolomide in glioma and melanoma cells. Oncotarget 7, 48081-48092. doi: 10.18632/oncotarget.10129

Rojo, A. I., Salinas, M., Martín, D., Perona, R., and Cuadrado, A. (2004). Regulation of $\mathrm{Cu} / \mathrm{Zn}$-superoxide dismutase expression via the phosphatidylinositol 3 kinase/Akt pathway and nuclear factor-kappaB. J. Neurosci. 24, 7324-7334. doi: 10.1523/JNEUROSCI.2111-04.2004

Rong, Y., Durden, D. L., Van Meir, E. G., and Brat, D. J. (2006). "Pseudopalisading” necrosis in glioblastoma: a familiar morphologic feature that links vascular pathology, hypoxia, and angiogenesis. J. Neuropathol. Exp. Neurol. 65, 529-539. doi: 10.1097/00005072-200606000-00001

Roos, W. P., Batista, L. F. Z., Naumann, S. C., Wick, W., Weller, M., Menck, C. F. M., et al. (2007). Apoptosis in malignant glioma cells triggered by the temozolomide-induced DNA lesion O6-methylguanine. Oncogene 26, 186-197. doi: 10.1038/sj.onc.1209785

Saitoh, M., Nishitoh, H., Fujii, M., Takeda, K., Tobiume, K., Sawada, Y., et al. (1998). Mammalian thioredoxin is a direct inhibitor of apoptosis signal-regulating kinase (ASK) 1. EMBO J. 17, 2596-2606. doi: $10.1093 / \mathrm{emboj} / 17.9 .2596$

Salaud, C., Alvarez-Arenas, A., Geraldo, F., Belmonte-Beitia, J., Calvo, G. F., Gratas, C., et al. (2020). Mitochondria transfer from tumor-activated stromal cells (TASC) to primary Glioblastoma cells. Biochem. Biophys. Res. Commun. 533:139-147. doi: 10.1016/j.bbrc.2020.08.101

Santos, P., and Almeida, F. (2020). Role of Exosomal miRNAs and the tumor microenvironment in drug resistance. Cells 9:1450. doi: 10.3390/cells9061450

Sattler, U. G. A., Meyer, S. S., Quennet, V., Hoerner, C., Knoerzer, H., Fabian, C., et al. (2010). Glycolytic metabolism and tumour response to fractionated irradiation. Radiother. Oncol. 94, 102-109. doi: 10.1016/j.radonc.2009. 11.007

Scherz-Shouval, R., Shvets, E., Fass, E., Shorer, H., Gil, L., and Elazar, Z. (2007). Reactive oxygen species are essential for autophagy and specifically regulate the activity of Atg4. EMBO J. 26, 1749-1760. doi: 10.1038/sj.emboj.7601623

Schiffer, D., Annovazzi, L., Casalone, C., Corona, C., and Mellai, M. (2018). Glioblastoma: microenvironment and niche concept. Cancers 11:5. doi: 10.3390/cancers11010005

Schreiber, J., Jenner, R. G., Murray, H. L., Gerber, G. K., Gifford, D. K., and Young, R. A. (2006). Coordinated binding of NF-kappaB family members in the response of human cells to lipopolysaccharide. Proc. Natl. Acad. Sci. U. S. A. 103, 5899-5904. doi: 10.1073/pnas.0510996103

Sedlak, T. W., and Snyder, S. H. (2004). Bilirubin benefits: cellular protection by a biliverdin reductase antioxidant cycle. Pediatrics 113, 1776-1782. doi: 10.1542 /peds.113.6.1776

Sharapov, M. G., and Novoselov, V. I. (2019). Catalytic and signaling role of peroxiredoxins in carcinogenesis. Biochem. Mosc. 84, 79-100. doi: 10.1134/S0006297919020019 
Shibao, S., Minami, N., Koike, N., Fukui, N., Yoshida, K., Saya, H., et al. (2018). Metabolic heterogeneity and plasticity of glioma stem cells in a mouse glioblastoma model. Neuro Oncol. 20, 343-354. doi: 10.1093/neuonc/nox170

Siddique, H. R., and Saleem, M. (2012). Role of BMI1, a stem cell factor, in cancer recurrence and chemoresistance: preclinical and clinical evidences. Stem Cells 30, 372-378. doi: 10.1002/stem.1035

Smith, A. G., and Macleod, K. F. (2019). Autophagy, cancer stem cells and drug resistance. J. Pathol. 247, 708-718. doi: 10.1002/path.5222

Smith, W. L., Garavito, R. M., and DeWitt, D. L. (1996). Prostaglandin endoperoxide $\mathrm{H}$ synthases (cyclooxygenases)-1 and-2. J. Biol. Chem. 271, 33157-33160. doi: 10.1074/jbc.271.52.33157

Soda, Y., Marumoto, T., Friedmann-Morvinski, D., Soda, M., Liu, F., Michiue, H., et al. (2011). Transdifferentiation of glioblastoma cells into vascular endothelial cells. Proc. Natl. Acad. Sci. U. S. A. 108, 4274-4280. doi: 10.1073/pnas.1016030108

Sporn, M. B., and Liby, K. T. (2012). NRF2 and cancer: the good, the bad and the importance of context. Nat. Rev. Cancer 12, 564-571. doi: 10.1038/nrc3278

Stepkowski, T. M., and Kruszewski, M. K. (2011). Molecular cross-talk between the NRF2/KEAP1 signaling pathway, autophagy, and apoptosis. Free Radic. Biol. Med. 50, 1186-1195. doi: 10.1016/j.freeradbiomed.2011.01.033

Storz, P. (2005). Reactive oxygen species in tumor progression. Front. Biosci. 10, 1881-1896. doi: 10.2741/1667

Stupp, R., Hegi, M. E., Mason, W. P., van den Bent, M. J., Taphoorn, M. J. B., Janzer, R. C., et al. (2009). Effects of radiotherapy with concomitant and adjuvant temozolomide versus radiotherapy alone on survival in glioblastoma in a randomised phase III study: 5-year analysis of the EORTC-NCIC trial. Lancet Oncol. 10, 459-466. doi: 10.1016/S1470-2045(09)70025-7

Stupp, R., Mason, W. P., van den Bent, M. J., Weller, M., Fisher, B., Taphoorn, M. J. B., et al. (2005). Radiotherapy plus concomitant and adjuvant temozolomide for glioblastoma. N. Engl. J. Med. 352, 987-996. doi: 10.1056/NEJMoa043330

Sullivan, R., Maresh, G., Zhang, X., Salomon, C., Hooper, J., Margolin, D., et al. (2017). The emerging roles of extracellular vesicles as communication vehicles within the tumor microenvironment and beyond. Front. Endocrinol. 8:194. doi: $10.3389 /$ fendo.2017.00194

Svendsen, A., Verhoeff, J. J. C., Immervoll, H., Brøgger, J. C., Kmiecik, J., Poli, A., et al. (2011). Expression of the progenitor marker NG2/CSPG4 predicts poor survival and resistance to ionising radiation in glioblastoma. Acta Neuropathol. 122, 495-510. doi: 10.1007/s00401-011-0867-2

Tamari, Y., Kashino, G., and Mori, H. (2017). Acquisition of radioresistance by IL- 6 treatment is caused by suppression of oxidative stress derived from mitochondria after $\gamma$-irradiation. J. Radiat. Res. 58, 412-420. doi: $10.1093 /$ jrr/rrw084

Tang, Z., and He, Z. (2019). TIGAR promotes growth, survival and metastasis through oxidation resistance and AKT activation in glioblastoma. Oncol. Lett. 18, 2509-2517. doi: 10.3892/ol.2019.10574

Tebay, L. E., Robertson, H., Durant, S. T., Vitale, S. R., Penning, T. M., DinkovaKostova, A. T., et al. (2015). Mechanisms of activation of the transcription factor Nrf2 by redox stressors, nutrient cues, and energy status and the pathways through which it attenuates degenerative disease. Free Radic. Biol. Med. 88, 108-146. doi: 10.1016/j.freeradbiomed.2015.06.021

Tedeschi-Blok, N., Lee, M., Sison, J. D., Miike, R., and Wrensch, M. (2006). Inverse association of antioxidant and phytoestrogen nutrient intake with adult glioma in the San Francisco Bay Area: a case-control study. BMC Cancer 6:148. doi: 10.1186/1471-2407-6-148

Tivnan, A., Zakaria, Z., O’Leary, C., Kögel, D., Pokorny, J. L., Sarkaria, J. N., et al. (2015). Inhibition of multidrug resistance protein 1 (MRP1) improves chemotherapy drug response in primary and recurrent glioblastoma multiforme. Front. Neurosci. 9:218. doi: 10.3389/fnins.2015.00218

Tlsty, T. D., and Coussens, L. M. (2006). Tumor stroma and regulation of cancer development. Annu. Rev. Pathol. 1, 119-150. doi: 10.1146/annurev.pathol.1.110304.100224

Tomasetti, C., Li, L., and Vogelstein, B. (2017). Stem cell divisions, somatic mutations, cancer etiology, and cancer prevention. Science 355, 1330-1334. doi: 10.1126/science.aaf9011

Trachootham, D., Alexandre, J., and Huang, P. (2009). Targeting cancer cells by ROS-mediated mechanisms: a radical therapeutic approach? Nat. Rev Drug Discov. 8, 579-591. doi: 10.1038/nrd2803
Traverso, N., Ricciarelli, R., Nitti, M., Marengo, B., Furfaro, A. L., Pronzato, M. A., et al. (2013). Role of glutathione in cancer progression and chemoresistance. Oxid. Med. Cell Longev. 2013:972913. doi: 10.1155/2013/972913

Tsai, J.-Y., Lee, M.-J., Dah-Tsyr Chang, M., and Huang, H. (2014). The effect of catalase on migration and invasion of lung cancer cells by regulating the activities of cathepsin S, L, and K. Exp. Cell Res. 323, 28-40. doi: 10.1016/j.yexcr.2014.02.014

Tsujii, M., Kawano, S., Tsuji, S., Sawaoka, H., Hori, M., and DuBois, R. N. (1998). Cyclooxygenase regulates angiogenesis induced by colon cancer cells. Cell 93 705-716. doi: 10.1016/S0092-8674(00)81433-6

Van Meir, E., Sawamura, Y., Diserens, A. C., Hamou, M. F., and de Tribolet, N. (1990). Human glioblastoma cells release interleukin 6 in vivo and in vitro. Cancer Res. 50, 6683-6688.

Vander Heiden, M. G., Cantley, L. C., and Thompson, C. B. (2009). Understanding the Warburg effect: the metabolic requirements of cell proliferation. Science 324, 1029-1033. doi: 10.1126/science.1160809

Vander Heiden, M. G., and DeBerardinis, R. J. (2017). Understanding the intersections between metabolism and cancer biology. Cell 168, 657-669. doi: 10.1016/j.cell.2016.12.039

Vaupel, P., and Mayer, A. (2007). Hypoxia in cancer: significance and impact on clinical outcome. Cancer Metastasis Rev. 26, 225-239. doi: 10.1007/s10555-007-9055-1

Vaupel, P., and Multhoff, G. (2017). Accomplices of the hypoxic tumor microenvironment compromising antitumor immunity: adenosine, lactate, acidosis, vascular endothelial growth factor, potassium ions, and phosphatidylserine. Front. Immunol. 8:1887. doi: 10.3389/fimmu.2017.01887

Vlashi, E., Lagadec, C., Vergnes, L., Matsutani, T., Masui, K., Poulou, M., et al. (2011). Metabolic state of glioma stem cells and nontumorigenic cells. Proc Natl Acad Sci U S A. 108, 16062-16067. doi: 10.1073/pnas.1106704108

Wang, H., Lathia, J. D., Wu, Q., Wang, J., Li, Z., Heddleston, J. M., et al. (2009). Targeting interleukin 6 signaling suppresses glioma stem cell survival and tumor growth. Stem Cells 27, 2393-2404. doi: 10.1002/stem.188

Wang, J., and Yi, J. (2008). Cancer cell killing via ROS: to increase or decrease, that is the question. Cancer Biol. Ther. 7, 1875-1884. doi: 10.4161/cbt.7.12.7067

Wang, K., and Klionsky, D. J. (2011). Mitochondria removal by autophagy. Autophagy 7, 297-300. doi: 10.4161/auto.7.3.14502

Wang, X.-J., Sun, Z., Villeneuve, N. F., Zhang, S., Zhao, F., Li, Y., et al. (2008). Nrf2 enhances resistance of cancer cells to chemotherapeutic drugs, the dark side of Nrf2. Carcinogenesis 29, 1235-1243. doi: 10.1093/carcin/bgn095

Weinberg, F., Ramnath, N., and Nagrath, D. (2019). Reactive oxygen species in the tumor microenvironment: an overview. Cancers (Basel) 11:1191. doi: $10.3390 /$ cancers 11081191

Whiteside, T. L. (2016). Tumor-derived exosomes and their role in cancer progression. Adv. Clin. Chem. 74, 103-141. doi: 10.1016/bs.acc.2015.12.005

Xu, P., Huecksteadt, T. P., and Hoidal, J. R. (1996). Molecular cloning and characterization of the human xanthine dehydrogenase gene (XDH). Genomics 34, 173-180. doi: 10.1006/geno.1996.0262

Yan, Y., Xu, Z., Dai, S., Qian, L., Sun, L., and Gong, Z. (2016). Targeting autophagy to sensitive glioma to temozolomide treatment. J. Exp. Clin. Cancer Res. 35:23. doi: 10.1186/s13046-016-0303-5

Ye, F., Zhang, Y., Liu, Y., Yamada, K., Tso, J. L., Menjivar, J. C., et al. (2013). Protective properties of radio-chemoresistant glioblastoma stem cell clones are associated with metabolic adaptation to reduced glucose dependence. PLoS One 8:e80397. doi: 10.1371/journal.pone.0080397

Yeh, S. H., Yang, W. B., Gean, P. W., Hsu, C. Y., Tseng, J. T., Su, T. P., et al. (2011). Translational and transcriptional control of Sp1 against ischaemia through a hydrogen peroxide-activated internal ribosomal entry site pathway. Nucleic Acids Res. 39, 5412-5423. doi: 10.1093/nar/gkr161

Yoshida, S., Tsutsumi, S., Muhlebach, G., Sourbier, C., Lee, M.-J., Lee, S., et al. (2013). Molecular chaperone TRAP1 regulates a metabolic switch between mitochondrial respiration and aerobic glycolysis. Proc. Natl. Acad. Sci. U. S. A. 110, E1604-1612. doi: 10.1073/pnas.1220659110

Zhang, P., Gao, J., Wang, X., Wen, W., Yang, H., Tian, Y., et al. (2017). A novel indication of thioredoxin-interacting protein as a tumor suppressor gene in malignant glioma. Oncol. Lett. 14, 2053-2058. doi: 10.3892/ol.2017.6397

Zhang, W., Wang, Z., Shu, F., Jin, Y., Liu, H., Wang, Q., et al. (2010). Activation of AMP-activated protein kinase by temozolomide contributes to apoptosis in 
glioblastoma cells via p53 activation and mTORC1 inhibition. J. Biol. Chem. 285, 40461-40471. doi: 10.1074/jbc.M110.164046

Zhang, Z., Xu, J., Chen, Z., Wang, H., Xue, H., Yang, C., et al. (2020). Transfer of microRNA via macrophage-derived extracellular vesicles promotes proneuralto-mesenchymal transition in glioma stem cells. Cancer Immunol. Res. 8, 966-981. doi: 10.1158/2326-6066.CIR-19-0759

Zhou, M., Sareddy, G. R., Li, M., Liu, J., Luo, Y., Venkata, P. P., et al. (2019). Estrogen receptor beta enhances chemotherapy response of GBM cells by down regulating DNA damage response pathways. Sci. Rep. 9:6124. doi: 10.1038/s41598-019-42313-8

Zhou, Y., Wang, H.-D., Zhu, L., Cong, Z.-X., Li, N., Ji, X.-J., et al. (2013). Knockdown of Nrf2 enhances autophagy induced by temozolomide in U251 human glioma cell line. Oncol. Rep. 29, 394-400. doi: 10.3892/or. 2012.2115

Zhu, J., Wang, H., Fan, Y., Hu, Y., Ji, X., Sun, Q., et al. (2014). Knockdown of nuclear factor erythroid 2-related factor 2 by lentivirus induces differentiation of glioma stem-like cells. Oncol. Rep. 32, 1170-1178. doi: 10.3892/or. 2014.3320
Zhu, J., Wang, H., Sun, Q., Ji, X., Zhu, L., Cong, Z., et al. (2013). Nrf2 is required to maintain the self-renewal of glioma stem cells. BMC Cancer 13:380. doi: 10.1186/1471-2407-13-380

Zhu, Z., Du, S., Du, Y., Ren, J., Ying, G., and Yan, Z. (2018). Glutathione reductase mediates drug resistance in glioblastoma cells by regulating redox homeostasis. J. Neurochem. 144, 93-104. doi: 10.1111/jnc.14250

Conflict of Interest: The authors declare that the research was conducted in the absence of any commercial or financial relationships that could be construed as a potential conflict of interest.

Copyright () 2021 Olivier, Oliver, Lalier and Vallette. This is an open-access article distributed under the terms of the Creative Commons Attribution License (CC BY). The use, distribution or reproduction in other forums is permitted, provided the original author(s) and the copyright owner(s) are credited and that the original publication in this journal is cited, in accordance with accepted academic practice. No use, distribution or reproduction is permitted which does not comply with these terms. 